\title{
Polyhydroxyalkanoate (PHA) purification through dilute aqueous ammonia digestion at elevated temperatures
}

Burniol-Figols, Anna; Skiadas, loannis V.; Daugaard, Anders E.; Gavala, Hariklia N.

Published in:

Journal of Chemical Technology and Biotechnology

Link to article, DOI:

$10.1002 / j c t b .6345$

Publication date:

2020

Document Version

Peer reviewed version

Link back to DTU Orbit

Citation (APA):

Burniol-Figols, A., Skiadas, I. V., Daugaard, A. E., \& Gavala, H. N. (2020). Polyhydroxyalkanoate (PHA)

purification through dilute aqueous ammonia digestion at elevated temperatures. Journal of Chemical

Technology and Biotechnology, 95(5), 1519-1532. https://doi.org/10.1002/jctb.6345

\section{General rights}

Copyright and moral rights for the publications made accessible in the public portal are retained by the authors and/or other copyright owners and it is a condition of accessing publications that users recognise and abide by the legal requirements associated with these rights.

- Users may download and print one copy of any publication from the public portal for the purpose of private study or research.

- You may not further distribute the material or use it for any profit-making activity or commercial gain

- You may freely distribute the URL identifying the publication in the public portal 
Title

\section{Polyhydroxyalkanoate (PHA) purification through dilute}

\section{aqueous ammonia digestion at elevated temperatures}

\section{Short title}

PHA purification through $\mathrm{NH}_{3}$ digestion at elevated temperatures

Anna Burniol-Figols, Ioannis V. Skiadas, Anders E. Daugaard and Hariklia N. Gavala*

Technical University of Denmark (DTU), Dept. of Chemical and Biochemical Engineering,

Søltofts Plads, Building 229, 2800 Kgs. Lyngby (Denmark)

*Corresponding author: hnga@kt.dtu.dk; hari_gavala@yahoo.com

This article has been accepted for publication and undergone full peer review but has not been through the copyediting, typesetting, pagination and proofreading process which may lead to differences between this version and the Version of Record. Please cite this article as doi: $10.1002 /$ jctb.6345 


\begin{abstract}
BACKGROUND: Purification of polyhydroxyalkanoates (PHA) is a challenging step, given the difficulty of achieving high PHA purity, while maintaining polymer integrity, in a sustainable and cost-efficient manner. This study evaluated the potential of dilute ammonia digestion as a method to purify PHA from mixed microbial consortia.
\end{abstract}

RESULTS: Digestion temperatures were critical to the obtainable purity and the amount of recovered PHA. At temperatures below $75^{\circ} \mathrm{C}$ (regardless of the incubation time and ammonia concentration), a low PHA recovery (down to $65 \%$ ) and no increase in purity was observed. By increasing the temperature above $75^{\circ} \mathrm{C}$, a significantly higher PHA purity and higher recovery (above $90 \%$ ) could be achieved. Temperatures maximizing the purity $\left(140^{\circ} \mathrm{C}\right)$ led to a detrimental reduction in the molar mass of the isolated PHA, but the use of a sonication pretreatment enabled to increase the purity at temperatures leading to limited molar mass loss (75$115^{\circ} \mathrm{C}$ ). The impurities still present in the recovered PHA did not compromise its thermal stability, and no significant degradation occurred during melting of PHA with 86 \% purity (comparably to pure chloroform-extracted PHA). Conversely, $\mathrm{PHA}$ recovered through $\mathrm{H}_{2} \mathrm{SO}_{4}$ digestion underwent severe degradation during melting, despite presenting higher purity (98 \%).

CONCLUSIONS: High PHA purity, recovery and thermal stability can be obtained with dilute ammonia digestion. These observations, combined with the possibility of reusing ammonia 
within the process, make this method a promising approach for a more sustainable purification of PHA.

\section{Introduction}

Polyhydroxyalkanoates (PHA) are bio-based and biodegradable polyesters produced in prokaryotic microbes as storage granules in the cytoplasm ${ }^{1}$. They have similar properties to polyethylene and polypropylene, and could replace these plastics in many of their applications. ${ }^{2}$ Several companies have brought PHA to industrial scale, but high production costs are still a major obstacle for a wider presence in the market. ${ }^{3}$

In the production stage, several strategies are being tested in order to reduce the costs, such as the use of waste substrates or mixed microbial consortia (MMC) instead of pure strains. ${ }^{3}$ After PHA production, the granules have to be extracted from the cells and purified from non-PHA cell material (NPCM), a step with significant impact on the overall costs and sustainability. ${ }^{3-5}$ The methods studied so far for PHA recovery and purification can be divided into two main categories based on their basic approach, described in the following paragraphs.

The first approach relies on the use of solvents to break the cell membranes and ultimately solubilise the PHA granules, which is typically attained with carcinogenic solvents like dichloromethane or chloroform. Subsequently, PHA is precipitated by the addition of a nonsolvent (e.g. methanol). Although lower efficiencies have been described for MMC compared to pure strains, ${ }^{6,7}$ these processes usually result in high PHA recovery and purity, while maintaining 
the integrity of the polymer. Nonetheless, these methods present obvious concerns in terms of safety and sustainability, and imply significant costs due to the large amounts of solvent and nonsolvent utilised. Substantial efforts are therefore being directed towards finding non-hazardous and easily recyclable organic solvents (such as ionic liquids) ${ }^{3-5}$, as well as towards identification of other more environmentally friendly processes.

The second approach for PHA purification aims at the digestion and solubilisation of the NPCM, leaving PHA as an insoluble solid. Such digestion processes can be biological (e.g. enzymes) or chemical. ${ }^{3}$ The major advantage of the latter is reduction of the processed volumes (compared to the use of solvents), as well as lower reagent costs. Several chemicals have been tested including alkalis (e.g. $\mathrm{NaOH}, \mathrm{KOH}$ or $\mathrm{NH}_{3}$ ), acids (e.g. $\mathrm{H}_{2} \mathrm{SO}_{4}$ ) surfactants (e.g. sodium dodecyl sulfate (SDS)) and oxidising agents (e.g. $\mathrm{NaOCl}$ ). High PHA purity and recovery (> $90 \%$ ) have been attained with some of these reagents (or combinations of them) both in pure strains and MMC. ${ }^{8-13}$ Nevertheless, the ester bonds of PHA are susceptible to hydrolysis and PHA degradation (reduction of molar mass) is usually reported as a significant drawback of these processes. ${ }^{8,9,11,13}$ In this sense, one of the most promising treatments so far is the use of dilute $\mathrm{H}_{2} \mathrm{SO}_{4}$ followed by $\mathrm{NaOCl}$. Limited PHA degradation (around $50 \%$ molar mass reduction) has been reported for this treatment, while achieving high PHA purity (up to $99 \%$ ) and a high recovery (up to $79 \%$ ). ${ }^{9,12,14}$

Besides PHA degradation, another disadvantage of the chemical digestion methods is the generation of significant volumes of wastewater containing chemicals. In this regard particularly, 
ammonia could bring important benefits to the process, given that $\mathrm{NH}_{3}$ (and other nutrients derived from NPCM digestion) could be used as a nitrogen source during the PHA production steps (and as such would not be considered a waste stream). Moreover, due to its high volatility, residual ammonia can more easily be separated from the extracted PHA, which could prevent negative effects of residual chemicals on the thermal stability of the polymer.

Ammonia digestion was first suggested in $1993,{ }^{15}$ when a PHA purity up to $94 \%$ was reported with no decrease in the molar mass by using relatively high ammonia concentrations $(1 \mathrm{~N})$ at $45^{\circ} \mathrm{C}$. In addition, the authors proved that $\mathrm{NH}_{3}$ could be successfully recycled as a nitrogen source for the PHA production. However, the strategy was only successful in strains with compromised cell membranes. Later on, a patent was published in which ammonia digestion at high concentrations (5-10 N) followed by NaOCl (4-6 \%) washing reached $92 \%$ PHA purity. No values of PHA recovery or polymer degradation were reported. ${ }^{16}$ Despite these encouraging results, little research has been dedicated to this digestion method. Some studies included ammonia in initial screenings, which generally resulted in lower PHA recoveries and purities compared to other alkalis (such as $\mathrm{NaOH}$ and $\mathrm{KOH}$ ), after which $\mathrm{NH}_{3}$ was excluded from further experiments..$^{13,17-19}$ To the extent of our knowledge, only two studies have reported the molar mass of PHA after $\mathrm{NH}_{3}$ digestion. ${ }^{15,20}$

Up to date, there has not been a comprehensive evaluation of the potential of $\mathrm{NH}_{3}$ digestion as a PHA purification method. There is lack of knowledge about the effect of digestion conditions on the PHA purity and polymer degradation. Likewise, there are no studies on the impact of $\mathrm{NH}_{3}$ 
digestion on the thermal stability under different conditions. The objective of the present study was therefore to investigate ammonia digestion with a focus, not only on PHA purity and recovery, but also on the effects on the polymer integrity (reduction of molar mass and thermal stability), which are commonly overlooked in PHA recovery studies.

\section{Materials and methods}

\subsection{Biomass for PHA purification experiments (crude PHA)}

Cells containing PHA were a MMC dominated by the genera Thauera and Ammaricoccus, obtained according to the process developed by Burniol-Figols et al.,. ${ }^{21}$ Briefly, the process consisted of three main steps: 1) Fermentation of crude glycerol into volatile fatty acids (butyrate, propionate and acetate) and 1,3-propanediol; 2) Enrichment of PHA-accumulating bacteria using synthetic volatile fatty acids and crude glycerol; 3) PHA accumulation using the biomass from step 2 as inoculum and the effluent of step 1 as substrate. In the last step volatile fatty acids were converted into $\mathrm{P}(3 \mathrm{HB}-\mathrm{co}-3 \mathrm{HV})$ (poly(3-hydroxybutyrate-co-3hydroxyvalerate)). After PHA accumulation, cells were centrifuged (4000 g 15 min), washed with distilled water and freeze-dried. In order to exclude sources of variation, the starting material for the PHA recovery assays was the end-product of 11 different PHA batch accumulations pooled together after freeze drying. The $\mathrm{P}(3 \mathrm{HB}-\mathrm{co}-3 \mathrm{HV})$ content of the joined biomass was $64 \pm 1.3 \mathrm{wt} \%$, where 3 -HV monomers represented a $13 \mathrm{wt} \%$ of the polymer. This starting material is referred in the text as crude PHA, and was kept in a desiccator in the dark. 


\subsection{Outline of experiments}

The first experiments evaluated the effect of the incubation time, the ammonia concentration and the temperature on the performance of the digestion of NPCM on crude PHA (detailed in section 2.3). The outcome of these experiments was mainly evaluated in terms of PHA purity and PHA recovery. Moreover, the latter parameter was complemented with the determination of the molar mass $\left(\overline{\mathrm{M}_{\mathrm{w}}}\right)$ of the recovered polymers and the quantification of PHA monomers lost in the supernatant to identify predominant hydrolysis patterns (leading to PHA loss or to reduction of $\overline{\mathrm{M}_{\mathrm{w}}}$ ). These analyses are described in section 2.6.

The trends in the hydrolysis observed at different temperatures were further investigated by two means. First, by evaluating how the equilibrium constants were affecting the hydrolysis rate at different temperatures. This was done by performing experiments with a simple ester (ethyl 3hydroxybutyrate (E3HB)) instead of PHA, in order to avoid possible bias from the polymer conformation (section 2.7). Secondly, by studying possible conformational changes occurring on PHA with different treatment conditions. This was attained by Differential Scanning Calorimetry (DSC) analysis on the polymers recovered with $\mathrm{NH}_{3}$ digestion at different temperatures (section 2.6).

Next, sonication was evaluated as a pre-treatment to increase the PHA purity at elevated temperatures ( 75 and $115^{\circ} \mathrm{C}$ ) (section 2.4). Lastly, the polymer recovered with the best conditions from this study was compared in terms of thermal stability (section 2.8) with PHA obtained through other suggested methods for PHA purification (section 2.5). 


\subsection{PHA purification through $\mathrm{NH}_{3}$ digestion}

PHA extraction experiments were performed by incubating $100 \mathrm{mg}$ of freeze-dried crude PHA with $4 \mathrm{~mL}$ of aqueous ammonia solution in pre-weighted $10 \mathrm{~mL}$ glass centrifuge tubes in a heating block. The tubes were vortexed every $5 \mathrm{~min}$. Different incubation times (10-60 min), temperatures $\left(30-140{ }^{\circ} \mathrm{C}\right)$ and ammonia concentration solutions $\left(0-1 \mathrm{M} \mathrm{NH}_{3}\right)$ were tested during the experiments. When one parameter was changed, the other remained at a central value: $30 \mathrm{~min}, 0.2 \mathrm{M}$ and $45^{\circ} \mathrm{C}$. All experiments were performed in triplicate. Ammonia solutions were prepared from concentrated ammonia solution $32 \mathrm{wt} \%$.

Unless otherwise stated, after incubation the tubes were allowed to cool at room temperature for $5 \mathrm{~min}$ and centrifuged for $5 \mathrm{~min}$ at $2500 \mathrm{~g}$ at room temperature. The time of centrifugation was increased to $15 \mathrm{~min}$ in samples incubated at $140{ }^{\circ} \mathrm{C}$ due to the observation of high turbidity. The supernatant was removed and the pellets containing the PHA were washed twice with $8 \mathrm{~mL}$ of distilled water and freeze-dried. The recovered material was analysed as described in section 2.6. All experiments were performed in triplicates.

\subsection{Sonication as a pre-treatment}

Sonication was performed in glass centrifuge tubes containing $100 \mathrm{mg}$ of freeze dried crude PHA suspended in $5 \mathrm{~mL}$ of distilled water and using a UP400S ultrasonic processor (400 W, $24 \mathrm{kHz}$, Heilscher) coupled to an H3 sonotrode (Heilscher) set to $100 \%$ amplitude and a pulse of 0.5 for $10 \mathrm{~min}$. Due to the energy delivered to the samples, the temperature increased to $70{ }^{\circ} \mathrm{C}$. 
After sonication, the tubes were centrifuged for $15 \mathrm{~min}$ at $2500 \mathrm{~g}$ and the pellets washed twice with distilled water. Thereafter, cell pellets were freeze-dried again to not introduce a dilution effect on the posterior $\mathrm{NH}_{3}$ digestion, which was performed as described above (15 min centrifugation time).

\subsection{PHA purification through reference methods}

$\mathrm{NaOH}$ digestion, as well as combined $\mathrm{NaOH}$ and SDS digestion, were performed according to the protocols suggested by Jiang et al., ${ }^{13}$. Incubations were done using $100 \mathrm{mg}$ of crude PHA and $4 \mathrm{~mL}$ of digestion solution, containing $\mathrm{NaOH} 0.2 \mathrm{M}$ or $\mathrm{NaOH} 0.2 \mathrm{M}$ with SDS $0.2 \%$ (w/v). Assay tubes were incubated at $30{ }^{\circ} \mathrm{C}$ for $60 \mathrm{~min}$, centrifuged (2500 g $\left.15 \mathrm{~min}\right)$ and washed twice with distilled water before freeze-drying the solids.

Acid mediated digestion was done as proposed in Lopez-Abelairas et al., ${ }^{9} .100 \mathrm{mg}$ of biomass was incubated with $2 \mathrm{~mL}$ of $\mathrm{H}_{2} \mathrm{SO}_{4} 3.5 \%$ (v/v) for $6 \mathrm{~h}$ at $80{ }^{\circ} \mathrm{C}$. Afterwards, the solution was adjusted to $\mathrm{pH} 10$ with $\mathrm{NaOH} 0.5 \mathrm{M}$, centrifuged $15 \mathrm{~min}$ at $2500 \mathrm{~g}$, and washed twice with distilled water. The recovered solids were then treated with $5.5 \mathrm{~mL}$ of $\mathrm{NaOCl} 3 \%(\mathrm{w} / \mathrm{v})$ for $1 \mathrm{~h}$ at room temperature, and again centrifuged and washed twice with distilled water before freezedrying. The recovered material was analysed as described in section 2.6. All experiments were performed in triplicates.

Chloroform extraction $\left(65^{\circ} \mathrm{C} 4 \mathrm{~h}\right.$ ) followed by methanol precipitation was performed as previously described. $^{22}$ 
2.6. Analyses on the material recovered after digestion experiments

For all digestion methods, the total solids recovered were assessed by weighing pre-tared tubes before and after the digestion and freeze-drying. PHA purity (expressed as g PHA/100 g solids) was measured by Gas Chromatography (GC) after HCl-mediated propanolysis in 1,2dichloroethane as previously described. ${ }^{22}$ Methyl-3-hydroxybutyrate (99\%, J\&K Scientific ${ }^{\circledR}$ ) and methyl-3-hydroxyvalerate ( $\geq 98 \%$, Sigma-Aldrich ${ }^{\circledR}$ ) were used as standards for the calibration of 3-HB and 3-HV monomers, given that the standard described in the referenced work ( $\mathrm{P}(3 \mathrm{HB}-\mathrm{co}-$ 3HV) with 12 mol\% 3-HV from Sigma-Aldrich ${ }^{\circledR}$ ) led to an average overestimation of $10 \%$ of the PHA purity (Supporting information -Appendix F). A secondary calibration curve was built with methyl-esters not submitted to the transesterification reaction dissolved in 1,2-dichloroethane, in order to take into account the extent of incomplete transesterification in the standard samples.

This value was then used to calculate the PHA recovery according to the following formula:

$$
\text { PHA recovery }(\%)=\frac{\text { PHA recovered }(g)}{\text { PHA initial }(g)} \cdot 100
$$

where

PHA recovered $(g)=$ solids after extraction $(g)$. PHA Purity after extraction ( $g$ PHA $/ g$ solids) PHA initial $(g)=$ solids before extraction $(g)$. PHA Purity before extraction ( $g$ PHA/g solids) The percentage of non-PHA cell material (NPCM) removed was assessed with the formula:

$$
\text { NPCM removal }(\%)=\frac{N P C M \text { removed }(g)}{N P C M \text { initial }(g)} \cdot 100
$$

where 


$$
\text { NPCM removed }(g)=\text { Solids removed }(g)-\text { PHA lost }(g)
$$

Solids removed $(g)=$ solids before extraction $(g)$ - solids after extraction $(g)$

PHA lost $(g)=$ PHA initial $(g)-$ PHA recovered $(g)$

NPCM initial $(g)=$ Solids before extraction $(g) \cdot(1-$ Purity PHA before extraction $((g$ PHA $/ g$ solids $))$

Molar mass distribution of the recovered material was assessed by Size Exclusion

Chromatography (SEC). The analyses were conducted in a Shimadzu HPLC (High Pressure

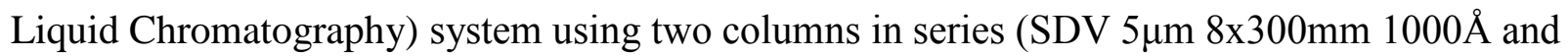

$10000 \AA$, PSS Polymer Standards Service GmbH). Chloroform was used as eluent at a flow rate

of $1 \mathrm{~mL} / \mathrm{min}$ with an oven temperature of $31^{\circ} \mathrm{C}$. Before analysis, $5 \mathrm{mg}$ of the recovered PHA

was dissolved in $1 \mathrm{~mL}$ of chloroform overnight and filtered through $0.45 \mu \mathrm{m}$ PTFE filters. The

system was calibrated with low dispersity polystyrene standards (Polymer Standards Service

GmbH). The copolymer P(3HB-co-3HV) with 12 mol\% 3-HV from Sigma-Aldrich ${ }^{\circledR}$ was used as a reference for comparisons.

For selected digestion conditions, the thermal behaviour of the PHA after digestion was assessed by Differential Scanning Calorimetry (DSC) (TA Instruments - Discovery series DSC) using hermetic aluminium pans. The first heating ramp (in order to erase thermal history) proceeded at a heating rate of $10{ }^{\circ} \mathrm{C} / \mathrm{min}$ from -90 to $185^{\circ} \mathrm{C}$ (run I), and was followed by a cooling ramp $\left(10^{\circ} \mathrm{C} / \mathrm{min}\right)$, and a second heating step (run II) identical to run I. The glass transition $\left(T_{g}\right)$ was determined at the inflection point, while crystallisation $\left(T_{c}\right)$ and melting $\left(T_{m}\right)$ temperatures were determined at the peak temperature on the second run. 
In experiments evaluating the temperature effect, additional analyses were performed in the supernatant of the digestion experiments. The concentration of 3-hydroxybutyrate (3-HB) and crotonic acid were determined in an HPLC system (Shimadzu) equipped with an Aminex HPX87H column (BioRad) with $12 \mathrm{mM} \mathrm{H}_{2} \mathrm{SO}_{4}(0.6 \mathrm{~mL} / \mathrm{min})$ at $40^{\circ} \mathrm{C}$. 3- $\mathrm{HB}$ was quantified through the refractive index detector signal, while crotonic acid was determined by the UV signal at 210 nm. Calibration curves were done with 3-hydroxybutyrate (HPC standards ${ }^{\circledR}$ ) and crotonic acid $98 \%$ (Sigma-Aldrich $\left.{ }^{\circledR}\right)$.

\subsection{Experiments on the hydrolysis rate using ethyl 3-hydroxybutyrate (E3HB)}

E3HB (100 mg) was incubated with $4 \mathrm{~mL}$ of $\mathrm{NH}_{3}$ solution $0.2 \mathrm{M}$ for different time intervals $(0,10,20$ and $30 \mathrm{~min})$ in duplicate, using the same materials and equipment used for the experiments in crude PHA. After incubation, tubes were cooled on ice for 5 min and immediately neutralised to $\mathrm{pH} 7$ with $\mathrm{H}_{3} \mathrm{PO}_{4}$. 3-HB and crotonic acid were determined by HPLC as described above (section 2.6). E3HB and ethanol were determined in a GC-FID (Agilent 6890) with a SGE BP21 column using nitrogen as a carrier gas. Samples were acidified with $\mathrm{H}_{3} \mathrm{PO}_{4}$ to $\mathrm{pH} 3$, and diluted 1:1 with acetone to enable $0.5 \mu \mathrm{L}$ split injections. Acetone used for dilution was spiked with 3-methyl-1-butanol (in order to verify that ester hydrolysis was not occurring before the analysis) and with 1-hexanol (internal standard to correct for injection variance). Ethyl-3-hydroxybutyrate (>99 \%, Acros Organics ${ }^{\circledR}$ ) and ethanol (99.9\%, Merck) were used as calibration standards. 


\subsection{Thermal stability}

Samples obtained with the different methods were analysed by Thermogravimetric Analysis (TGA) (TA Instruments - Discovery series TGA). The analyses were run under nitrogen at a rate of $20^{\circ} \mathrm{C} / \mathrm{min}$ and in a temperature range from 25 to $700{ }^{\circ} \mathrm{C}$ coupled with gas analysis on a FT-IR (Thermoscientific iS10) equipped with a gas-cell. Moreover, thermal stability during melt was

assessed by determining the $\overline{\mathrm{M}_{\mathrm{w}}}$ change after melting the recovered polymers in a hot press (170 ${ }^{\circ} \mathrm{C}$ for $5 \mathrm{~min}$ ) in duplicate.

\section{Results and discussion}

\subsection{Effect of time and $\mathrm{NH}_{3}$ concentration on ammonia digestion}

Effects of different digestion times (10-60 min) and ammonia concentrations (0-1 $\left.\mathrm{M} \mathrm{NH}_{3}\right)$ were investigated at a constant temperature $\left(45^{\circ} \mathrm{C}\right)$. The main results in terms of PHA recovery, PHA purity and elimination of NPCM (non-PHA cell material) are presented in Figure 1.

Long incubation times had a detrimental effect for the PHA recovery, while little effect on the NPCM removal (Figure $1 \mathrm{~A}$ ). As PHA and impurities were lost in a similar degree, the samples maintained a PHA purity similar to the material before digestion. In short, longer incubation times seemed to contribute more to the loss of PHA than to the increase of PHA purity.

Similar trends were observed when increasing the ammonia concentration (Figure 1 B). PHA recovery decreased progressively from 80 to $66 \%$, while the percentage of impurities removed was independent of the ammonia concentration (approximately $25 \%$ of NPCM removal). PHA 
purity presented a slight decline with increasing ammonia concentrations, as a result of a combination of decreased PHA recovery and steady NPCM removal. At the highest concentration of ammonia, PHA purity was even lower than in crude PHA (61 \% vs 64 \%). A certain loss of PHA (around $12 \%$ ) and NPCM removal (6.2 \%) was also observed in the control experiment without ammonia (distilled water) (Figure $1 \mathrm{~B})$.

Despite the fact that rather low PHA recoveries were obtained with these experiments (65 - 82 \%), no indications of significant PHA degradation were observed. The recovered polymers

presented very similar values of average molar mass $\left(\overline{\mathrm{M}_{\mathrm{w}}}\right)$ and dispersity $(Đ)$ to the crude PHA in all the conditions assayed (Table S1).

\subsection{Effect of temperature on ammonia digestion}

Besides ammonia concentration and time, temperature was also evaluated as a parameter influencing the effectiveness of the PHA recovery through ammonia digestion (Figure 2).

An important decrease in the PHA recovery (from 82 to $72 \%$ ) was observed when increasing the temperature from 30 to $45^{\circ} \mathrm{C}$, without being accompanied by an increase in the purity (Figure 2 A). Nonetheless, the opposite effect was observed when the temperature was further increased to $75^{\circ} \mathrm{C}$. At this temperature, a higher PHA purity and recovery were obtained (68 and $88 \%$, respectively), and more NPCM was solubilised. Consequently, incubation at $75^{\circ} \mathrm{C}$ seemed to affect the impurities more than the PHA itself. No significant changes were observed in molar mass $\left(\overline{\mathrm{M}_{\mathrm{w}}}\right)$ or $Đ$ for any of the temperatures with respect to the original material at this temperature range (Figure $2 \mathrm{~B}$ ). 
At $115^{\circ} \mathrm{C}$ and $140{ }^{\circ} \mathrm{C}$, PHA purity reached even higher values (75 and $83 \%$, respectively), while maintaining high PHA recovery (almost 90 \%) (Figure 2 A). For all temperatures, 3-HB and 3-HV monomers were recovered to a similar extent. However, incubations at elevated temperatures resulted in a considerable decrease in the molar mass of the recovered polymer (Figure 2 B). At $115^{\circ} \mathrm{C}$, extraction led to a molar mass similar to that of commercially available PHA ( $\left(\overline{\mathrm{M}_{\mathrm{w}}}\right.$ of around $\left.200 \mathrm{~kg} / \mathrm{mol}\right)$, while extraction at $140{ }^{\circ} \mathrm{C}$ led to a lower molar mass $\left(\overline{\mathrm{M}_{\mathrm{w}}}\right.$ of $85 \mathrm{~kg} / \mathrm{mol})$. Differences in Đ were statistically non-significant ( $\mathrm{p}>0.05)$.

Mechanical properties of polymers are affected by their molar mass, usually following an asymptotical trend. ${ }^{23}$ For example, the tensile strength of polymers is generally compromised at low molar mass, but does not increase further once a molar mass threshold is surpassed. Hence, loss of molar mass does not necessary imply detrimental effects in a polymer's properties. The molar mass threshold varies among polymer properties, and it is also affected by the monomer distribution and the polymer purity. Thus, a limit of acceptable molar mass cannot be established without a characterisation of a range of mechanical parameters, as well as taking its life-span degradation mechanism into account. Having said that, other studies have reported deteriorated properties for $\mathrm{P}(3 \mathrm{HB}-\mathrm{Co}-3 \mathrm{HV})$ with $\overline{\mathrm{M}_{\mathrm{w}}}$ below $112 \mathrm{~kg} / \mathrm{mol} .{ }^{24}$ Hence, digestion at $140{ }^{\circ} \mathrm{C}$ would not be recommended, due to the loss in molar mass. However, the treatment at $115^{\circ} \mathrm{C}$ would still lead to an a priori acceptable value (200 kg/mol).

It is important to note that only the temperature was studied as a parameter in these experiments, whereas the ammonia concentration and the incubation time were maintained at 
constant values (0.2 M, $30 \mathrm{~min})$. Nonetheless, negative effects of long incubation times and high ammonia concentrations upon the PHA recovery were described in the previous section. To observe the effect of the incubation time at these temperatures, an experiment at $115{ }^{\circ} \mathrm{C}$ for only 15 min (vs. 30 min in Figure 2) was performed. With only 15 min difference, the polymer degradation was reduced from $67 \%$ to $38 \%$, while PHA purity was only reduced from 75 to $72 \%$. Thus, a high sensitivity to digestion parameters was observed at high temperature, contrasting the minor changes observed at low temperatures (Figure 1). Consequently, a finetuning of variables in a multivariate approach, as well as a consideration of the importance of a high purity product versus molar mass, would be needed in order to identify specific conditions.

\subsection{Why higher PHA recovery at elevated temperatures?}

In general, the use of elevated temperatures led to a high degree of PHA purity, which can be attributed to the tendency of most compounds to increase their solubility in water at increasing temperatures. Moreover, the rate of hydrolysis reactions increases with temperature, resulting in faster digestion of NPCM. Similarly, a higher degree of PHA degradation would also be expected, as the rate of ester bond cleavage reactions - hydrolysis and/or $\beta$-elimination - increase with temperature. Counterintuitively, PHA recovery improved with increasing temperature (Figure 2). The following sections (3.3.1-3.3.3) elaborate further on this phenomenon, and its possible causes. 


\subsubsection{PHA loss vs. reduction in the PHA molar mass}

In the digestion experiments, ester cleavage phenomena are reflected in two different measured responses: PHA recovery and reduction of molar mass. The reduced PHA recovery would account for the ester bonds breakage occurring towards the end of the polymer chains, leading to the formation of soluble oligomers and monomers that would be lost in the supernatant, resulting in PHA loss. Conversely, ester cleavage occurring at the middle of the chains would produce shorter chains (reduction of molar mass), but still result in water-insoluble polymers that would be recovered in the solid fraction. The occurrence of these two degradation phenomena is summarised in Figure 3 A, showing opposite trends with temperature. At low temperatures PHA loss predominated, whereas at high temperatures reduction in $\overline{\mathrm{M}_{\mathrm{w}}}$ was more pronounced. The inflection point was between 45 and $75^{\circ} \mathrm{C}$.

PHA recovery could not be significantly increased by raising the centrifugation speed (from 2500 to 4300 g), nor by solid-liquid separation through filtration (Figure S1 Supporting information - Appendix B). Similarly, no significant increment in the PHA recovery was obtained by decreasing the centrifugation temperature to $4{ }^{\circ} \mathrm{C}$ or with a previous cooling of the solution (Figure S1), which has been reported to result in enhanced precipitation and increased PHA recovery in previous studies employing $\mathrm{NaOH}^{25}$

In order to further confirm that PHA loss was indeed due to the formation of soluble monomers and oligomers - and not due to the loss of long PHA chains during the solid-liquid 
separation - 3-hydroxybutyrate (3-HB) and crotonic acid were analysed in the supernatants of the $\mathrm{NH}_{3}$ digestions at different temperatures (Figure $3 \mathrm{~B}$ ).

Crotonic acid was only detected in trace amounts, representing less than $1 \%$ of the $3-\mathrm{HB}$ monomers lost. Its concentration increased exponentially with temperature, similarly to the trend observed for the reduction of $\overline{\mathrm{M}_{\mathrm{w}}}$ (Figure $3 \mathrm{~A}$ ). This was in good agreement with previous findings, which attributed the generation of crotonic acid to $\beta$-elimination reactions occurring in the P3HB backbone. This reaction is the predominant mechanism of chain scission and $\overline{\mathrm{M}_{\mathrm{w}}}$ reduction at elevated temperatures. ${ }^{14,26}$

On the other hand, the amount of 3-HB in the supernatants (resultant from P3HB hydrolysis) presented the same trend as the PHA loss, with a maximum at $45{ }^{\circ} \mathrm{C}$. The quantified 3-HB represented more than $60 \%$ of the 3 -HB monomers lost at temperatures up to $75^{\circ} \mathrm{C}$. This result confirmed a higher degree of hydrolysis leading to monomer formation occurring at temperatures below $75{ }^{\circ} \mathrm{C}$, which resulted in PHA loss. Given that this trend was unexpected, further experiments were performed to elucidate if the phenomena could be related to changes in the hydrolysis rate, or to changes in the conformational structure of PHA. These experiments are presented and discussed in the following two sections (3.3.2 and 3.3.3).

\subsubsection{Changes in the hydrolysis rates with digestion temperature}

The rate of basic-catalysed hydrolysis of esters is generally dependent on the concentration of hydroxide ions $\left(\mathrm{OH}^{-}\right)$, which act as nucleophiles in the reaction. However, in aqueous ammonia solutions, unionised ammonia $\left(\mathrm{NH}_{3}\right)$ can also act as a nucleophile and cleave ester bonds 
(producing primary amides). The overall rate of the reaction can be expressed as a function of the reaction constants $(k)$ and the concentration of $\mathrm{OH}^{-}$and $\mathrm{NH}_{3}$ (eq.1).

$$
\begin{gathered}
d[\text { ester }] / d t=\left(k_{\mathrm{OH}}[\mathrm{OH}]+k_{\mathrm{NH}_{3}}\left[\mathrm{NH}_{3}\right]\right) .[\text { ester }] \\
\left.d[\text { ester }] / d t=k_{\text {obs }} \text { [ester }\right]
\end{gathered}
$$

By increasing the temperature, the reaction constants ( $\mathrm{k}_{\mathrm{OH}}$ and $\mathrm{k}_{\mathrm{NH}}$ ) increase exponentially (according to the Arrhenius equation). However, the temperature also affects the dissociation constants of water and ammonia, as well as their vapour pressures. This translates into changes in the effective concentration of $\mathrm{OH}^{-}$and unionised $\mathrm{NH}_{3}$, which could affect the overall reaction rate. To simulate the changes in the $\mathrm{OH}^{-}$and $\mathrm{NH}_{3}$ concentrations occurring due to temperature increase, a theoretical model was constructed, taking into account the equilibrium reactions of $\mathrm{NH}_{3}$ and water, and the vapour-liquid equilibrium of $\mathrm{NH}_{3}$ (Figure 4 and Supporting information Appendix C).

The most interesting result of this model was the trend of pOH with the temperature (Figure 5). Maximum $\mathrm{OH}^{-}$concentration was identified at $45^{\circ} \mathrm{C}$, coinciding with the maximum PHA loss presented in Figure 3. This trend was a result of the ammonia ionisation reaction, which is endothermic under $50{ }^{\circ} \mathrm{C}$, but exothermic at higher temperatures (Figure 4). ${ }^{27}$ Consequently, and according to the Van Hoff Equation, the equilibrium shifts to $\mathrm{NH}_{4}{ }^{+}$with increasing temperatures up to $50{ }^{\circ} \mathrm{C}$, resulting in higher concentration of $\mathrm{OH}^{-}$, but does the opposite for higher temperatures (Figure 5). 
The model showed only small changes in the concentration of $\mathrm{OH}^{-}$and unionised $\mathrm{NH}_{3}$ at different temperatures. These changes would not seem enough to overrule the effect of temperature in increasing the rate constants and decrease the overall hydrolysis rate (as expressed in eq.1). Nonetheless, given the correlation between the concentration of $\mathrm{OH}^{-}$and the PHA loss (attributed to PHA hydrolysis in the previous section), the overall hydrolysis rate at different temperatures was assessed experimentally. The experiments were performed by submitting ethyl-3-hydroxybutyrate (E3HB) to $\mathrm{NH}_{3}$ digestion at different temperatures, as previously done with crude PHA (Figure 2 and 3). By replacing PHA for E3HB as a model ester, bias in the hydrolysis rate dues to conformational changes of the polymer was excluded.

For each temperature, the concentration of $\mathrm{OH}^{-}$and $\mathrm{NH}_{3}$ were assumed to be constant during the reaction, and the overall reaction constant $\left(\mathrm{k}_{\mathrm{obs}}\right)$ was calculated based on a pseudo-first order reaction kinetics (eq.2). The results showed an increase in $\mathrm{k}_{\mathrm{obs}}$ at increasing temperature (Figure 6), which enabled two important inferences: 1) the decrease in $\mathrm{OH}^{-}$at elevated temperatures was not enough to overrule the increase in the reaction constants; and 2) the decrease of hydrolysis at elevated temperatures exposed in Figure 3 could not be explained by a decrease in the hydrolysis rate. Further investigations were centred on the conformation of PHA and presented in the next section (3.3.3).

In regards to the products identified from E3HB hydrolysis, only trace amounts of crotonic acid were detected, falling below the quantification limit $(0.9 \mathrm{mg})$. Ethanol and 3-HB were the prevailing products, and were determined practically in equimolar concentrations (as exemplified 
in Figure 6 B corresponding to the experiment at $140^{\circ} \mathrm{C}$ ). This enabled another important conclusion from these experiments, which was that $\mathrm{OH}^{-}$catalysed hydrolysis of the ester bond (leading ethanol and 3-HB) was clearly predominant over ammonolysis (resulting in ethanol and 3-hydroxybutyramide) at the conditions studied. Consequently, a high presence of amide groups would not be expected in the recovered polymer.

\subsubsection{Changes in the PHA conformation with digestion temperature}

PHA decomposition is known to be affected by the polymer conformation, as highly crystalline polymers are more resistant to alkali attack. ${ }^{14}$ Therefore, thermal transitions occurring in the crude PHA submitted to different digestion temperatures were examined by DSC analysis (Figure 7).

In crude PHA, the glass transition $\left(\mathrm{T}_{\mathrm{g}}\right)$ was identified at $-6.8^{\circ} \mathrm{C}$, the melting temperature $\left(\mathrm{T}_{\mathrm{m}}\right)$ at $156{ }^{\circ} \mathrm{C}$, and a small cold crystallisation $\left(\mathrm{T}_{\mathrm{c}}\right)$ was observed around $50^{\circ} \mathrm{C}$ (Figure $7 \mathrm{~B}$ ). The samples purified through $\mathrm{NH}_{3}$ digestion at different temperatures presented the same thermal profile, although the enthalpies of the phenomena were much more pronounced (Figure 7 B). This indicated that the samples had a higher degree of crystallinity than the crude PHA, most likely due to the removal of impurities that compromised the formation of crystalline structures in the crude PHA.

Cold crystallisation was only observed in the second run of the DSC (after cooling from the molten state), and not in the first heating curve (Figure 7 A). Instead, the first run exhibited a "shoulder" in the DSC baseline at around $60^{\circ} \mathrm{C}$. In reference to Figure $7 \mathrm{~A}$, it should be noted 
that the curve presented as well some sharp endotherms at temperatures above $120{ }^{\circ} \mathrm{C}$. These peaks were attributed to the evaporation of impurities resulting in leakages from the capsules, as presented in the Supporting information (Appendix D).

The thermal transition observed in the first heating curve at $60{ }^{\circ} \mathrm{C}$ (Figure $7 \mathrm{~A}$ ) - hereafter $\mathrm{T}_{\mathrm{g} 2}$ has previously been reported for samples stored at room temperature, ${ }^{28-30}$ and has been attributed to the glass transition temperature of the rigid amorphous fraction (RAF). ${ }^{30}$ The RAF is formed even after very short periods $(<24 \mathrm{~h})$ of storage at temperatures above the glass transition temperature of the mobile amorphous fraction. ${ }^{31}$ During this process, the amorphous regions in contact with the crystals undergo a restriction of mobility. Moreover, small imperfect interlamellar crystallites are formed (secondary crystallisation) which further constrains the mobility of the amorphous regions. ${ }^{29,31-33}$ Above the $\mathrm{T}_{\mathrm{g}}$ of the RAF, melt and recrystallisation start occurring, which translates into a negative slope in the DSC curve until the melting of the primary lamellae occur at the $\mathrm{T}_{\mathrm{m}}{ }^{30}$

The secondary crystallisation of PHA has been widely studied, given its effect on the mechanical properties of the polymer, and it has been found to be reversible after annealing polymers at temperatures above $\mathrm{T}_{\mathrm{g} 2 .}{ }^{29,31,32}$ The heating step enables the melting of the imperfect crystallites developed during secondary crystallisation, as well as mobilisation of the rigid amorphous fraction, which allows a reorganisation of the amorphous fraction and a thickening of the stable crystallites. ${ }^{31,33}$ 
The abovementioned phenomenon could be a potential explanation for the decrease in PHA loss observed above $75^{\circ} \mathrm{C}$ (Figure 3). By incubating PHA above the $\mathrm{T}_{\mathrm{g} 2}\left(60^{\circ} \mathrm{C}\right)$, there is a mobilisation of the RAF, which could enable the formation of thicker crystals. Moreover, digestion above $75^{\circ} \mathrm{C}$ led to a higher release of impurities possibly compromising crystallisation. Both factors would contribute to a higher degree of crystallinity, and thus, possibly explain a lower degree of hydrolysis leading to PHA loss.

On the other hand, the start of the endotherm observed above $100{ }^{\circ} \mathrm{C}$ (Figure $7 \mathrm{~B}$ ) would indicate a progressive melting of the crystalline structure, thus making the chains more accessible to hydrolysis in the middle of the chains. This fact, together with the onset of the exponential increase in $\beta$-elimination reactions at elevated temperatures (resulting in crotonic acid formation - Figure 3) could be a reasonable hypothesis to explain the higher degree of reduction of molar mass observed from $115^{\circ} \mathrm{C}$.

\subsection{Sonication pre-treatment to increase the PHA purity}

Ammonia digestion at elevated temperatures proved to be a valuable method to increase the PHA purity while maintaining high recovery yields. Nonetheless, severe reduction of the molar mass was observed at conditions favouring high purity $\left(140^{\circ} \mathrm{C}\right)$ (Figure 2$)$. Thus, a sonication pre-treatment was investigated as a strategy to enhance ammonia digestion at lower temperatures. Sonication was chosen based on its reported efficiency in disaggregating the exopolysaccharide structures of microbial cultures, ${ }^{34,35}$ which have been suggested as the main 
reason behind the recalcitrance of MMC to PHA extraction. ${ }^{6,7}$ The results of these experiments are displayed in Figure 8.

Through sonication as the only means of purification (control without posterior $\mathrm{NH}_{3}$ digestion), a PHA purity of almost $70 \%$ was reached (Figure 8 A). $33 \%$ of the impurities were removed with this physical treatment, resulting in only 11 \% PHA loss. However, a certain reduction of the molar mass was observed compared to the starting material (Figure $8 \mathrm{~B}$ ). When sonication was followed by ammonia digestion at 75 or $115^{\circ} \mathrm{C}$, PHA purity reached a value of 79 and $86 \%$, respectively (Figure 8 A). These values represented a $15 \%$ relative increase in the PHA purity compared to the non-pretreated ammonia digestion at the same temperatures (Figure 2), without affecting PHA recovery. The average molar mass did not decrease significantly with the treatment at $75^{\circ} \mathrm{C}$ after sonication (Figure $8 \mathrm{~B}$ ), in agreement with observations for samples without sonication at this temperature (Figure 2 B). The treatment at $115^{\circ} \mathrm{C}$ led to a similar value of $\overline{\mathrm{M}_{\mathrm{w}}}$ as without pretreatment (around $200 \mathrm{~kg} / \mathrm{mol}$ ), and thus, still within a priori acceptable ranges according to the discussion in section 3.2. A distinctly whiter polymer was obtained after this treatment.

\subsection{Thermal stability of $\mathrm{NH}_{3}$ purified samples (comparison with reference methods)}

The thermal stability of the PHA purified through $\mathrm{NH}_{3}$ digestion $\left(\mathrm{NH}_{3} 0.2 \mathrm{M}\right.$ at $115^{\circ} \mathrm{C}$ with sonication) was evaluated and compared to other previously suggested methods aiming at the solubilisation of the NPCM (summarised in Table 1). Namely, the methods included digestion 
with $\mathrm{NaOH}$, combined $\mathrm{NaOH}$ and SDS, and $\mathrm{H}_{2} \mathrm{SO}_{4}$ treatment. Moreover, chloroform extraction was used as a reference method, for being known as a method not leading to PHA degradation.

Previous studies on alkali extraction have reported up to $96 \%$ PHA purity by using $\mathrm{NaOH}$, and up to $99 \%$ when combined with SDS. ${ }^{13}$ When applied to the crude PHA from the present study, these methods led to 72 and $76 \%$ purity, respectively (Table 1), giving further indication of the recalcitrance of the mixed microbial culture used for the PHA production. No important decrease in molar mass was observed in the recovered PHA with either method (Figure 9). PHA recovery was approximately $90 \%$ for both treatments.

Sulphuric acid digestion followed by mild $\mathrm{NaOCl}$ treatment has so far been identified as the most promising method for solubilising NPCM, due to the notable outcomes in terms of PHA purity and the limited extend of the PHA degradation. ${ }^{9,12,14}$ Moreover, it presented less $\mathrm{CO}_{2}$ emissions and costs compared to methods employing $\mathrm{NaOCl}$ or solvents. ${ }^{9}$ In the present study, $\mathrm{H}_{2} \mathrm{SO}_{4}$ treatment gave indeed practically pure PHA and a $97 \%$ PHA recovery (Table 1$)$. The $\overline{\mathrm{M}_{\mathrm{w}}}$ after digestion was in the range of the one obtained after ammonia extraction at $115{ }^{\circ} \mathrm{C}$ (about 200 kg/mol) (Figure 9).

The samples purified through the different methods were submitted to TGA analysis to observe their thermal stability (Figure $10 \mathrm{~A}$ ). All samples presented a major drop in mass at temperatures between $200-330^{\circ} \mathrm{C}$, corresponding to the thermal decomposition of PHA. Infrared spectra obtained in-line confirmed the presence of crotonic acid in the off-gas during this temperature range. Only the samples purified with chloroform and $\mathrm{H}_{2} \mathrm{SO}_{4}$ presented an almost 
complete loss of mass during PHA degradation, indicating the high purity of the samples. The rest of the analysed samples presented further weight loss until $550{ }^{\circ} \mathrm{C}$, representing the presence of other organic compounds. Furthermore, total weight loss was not observed at the end of the heating ramp $\left(700^{\circ} \mathrm{C}\right)$, which pointed out the presence of residual inorganics. The content of organic and inorganic impurities calculated from these mass loses, as well as the PHA percentage (calculated from the mass loss in the main slope) are presented in Table 1. The PHA purity calculated from the TGA gave similar results to that obtained by GC.

Figure $10 \mathrm{~B}$ shows the derivative curve of the TGA, where the position of the peaks indicates the temperature of maximum PHA decomposition $\left(\mathrm{T}_{\mathrm{d}}\right)$. PHA purified through ammonia digestion presented a $\mathrm{T}_{\mathrm{d}}$ above $300{ }^{\circ} \mathrm{C}$, very close to the sample purified with chloroform. On the other hand, the samples purified through $\mathrm{NaOH}$ or $\mathrm{H}_{2} \mathrm{SO}_{4}$ presented much lower values. More specifically, the $T_{d}$ for the acid purified sample was in the range of the crude PHA (without any purification), while the alkali methods led to an even lower $T_{d}$ than the starting material. Thus, the thermal stability of the purified material did not seem to be related to the degree of PHA purity obtained with different methods. Likewise, no correlation was identified between the $T_{d}$ and the quantities of organic or inorganic impurities determined from the TGA curve.

An absence of correlation between the $T_{d}$ and the purity was also observed when comparing the samples obtained through ammonia digestion at different conditions (Figure $10 \mathrm{C}$ ). $T_{\text {The }} \mathrm{T}_{\mathrm{d}}$ of all these samples was in line with the one of the chloroform purification, although the purity of these samples was much lower. Especially noteworthy is the case of the sample purified at $75^{\circ} \mathrm{C}$ 
compared to the crude PHA, where just an increase of $4 \%$ in the PHA purity (from 64 to $68 \%$ ) led to an increase of the $\mathrm{T}_{\mathrm{d}}$ of $36{ }^{\circ} \mathrm{C}$ (from 265 to $301^{\circ} \mathrm{C}$ ).

The $T_{d}$ is an important indication of the thermal stability of PHA, but it only accounts for PHA degradation resulting in absolute mass loss, occurring generally at temperatures above $250{ }^{\circ} \mathrm{C}$. Chain scission reactions are known to occur at much lower temperatures, close to the melting temperature, and lead to reduction of the molar mass without absolute mass loss ${ }^{26,36}$ (and thus not observed in the TGA). This degradation has important implications during polymer processing.

Crude PHA, as well as samples purified through the different comparison methods were melted at $170{ }^{\circ} \mathrm{C}$ in a hot press in order to observe changes in molar mass (Figure 9). Severe reduction of molar mass (86 \%) was observed in samples treated with $\mathrm{NaOH}$ or $\mathrm{H}_{2} \mathrm{SO}_{4}$, all leading to $\overline{\mathrm{M}_{\mathrm{w}}}$ 's below $100 \mathrm{~kg} / \mathrm{mol}$. Interestingly, these samples presented almost twice the reduction of molar mass compared to the crude PHA. Conversely, $\mathrm{NH}_{3}$-purified PHA $\left(115^{\circ} \mathrm{C}\right.$ with previous sonication) showed only a $10 \%$ reduction of molar mass, comparable to the degradation observed for chloroform-extracted PHA.

While no important differences were observed in the TGA with regards to the $T_{d}$ of samples obtained with $\mathrm{NH}_{3}$ digestion under different conditions (Figure $10 \mathrm{C}$ ), significant differences were observed in the melt-stability (Figure 9). Higher purities correlated with an increase in the thermal stability, although samples with higher than 70 \% PHA purity presented already a low reduction in the molar mass. 
Overall, the results suggested that biomass and fermentation residues had a limited effect on catalysing thermal degradation, whereas the method of purification had a drastic impact. A potential explanation could be the nature of the chemicals used. $\mathrm{H}_{2} \mathrm{SO}_{4}$ and $\mathrm{NaOH}$ are difficult to remove completely from the recovered polymer, and traces of such chemicals can catalyse degradation reactions during melting. On the other hand, $\mathrm{NH}_{3}$ is highly volatile, and can easily be removed.

Several studies have led to similar observations in regards to the effect of the biomass residues and the purification methods on the thermal stability. ${ }^{11,13,28,37,38}$ In addition, it has been reported that some impurities can behave as plasticisers, enhancing the mechanical properties of PHA, ${ }^{28,38}$ which emphasise the importance of testing other properties besides the PHA purity when evaluating purification methods. The presence of impurities should only be considered detrimental when affecting negatively the PHA properties and applicability.

\subsection{Comparison of results obtained with ammonia digestion and perspectives}

Ammonia-assisted extraction of PHA has not been extensively reported in scientific literature. Discrepancies have been reported in regards to the outcomes observed at similar conditions in different cultures (Table 2). As an example, by applying the same digestion conditions, Anis et al. ${ }^{17}$ observed no increase of the PHA purity accompanied with very low PHA recoveries, whereas Choi and Lee ${ }^{18}$ observed an important increase in the PHA purity and high PHA recovery. Likewise, no increase in the PHA purity was observed when increasing the temperature from $45^{\circ} \mathrm{C}$ to $100{ }^{\circ} \mathrm{C}$ in the study of Page and Cornish ${ }^{15}$, whereas significant 
improvements in the efficiency of the extraction were observed in the present study with a similar temperature increase (Figure 2). Higher PHA purity and recovery were also observed at elevated temperatures using $\mathrm{NH}_{3}$-laurate digestion in MMC. ${ }^{19}$ These differences might imply that the efficiency of dilute aqueous ammonia digestion depends on the PHA accumulating culture.

Most of the studies up to now, have only tested $\mathrm{NH}_{3}$ digestion in a screening phase, and discarded the method due to lower initial PHA purity and recovery compared to other alkalis (such as $\mathrm{NaOH}, \mathrm{KOH}$ or $\mathrm{NH}_{3}$-laurate). ${ }^{13,17-19}$ Nonetheless, the whole picture of the results obtained here and reported previously, suggests that $\mathrm{NH}_{3}$ digestion efficiency largely depends on the digestion conditions (and possibly on the PHA accumulating culture), and that adjustment of the parameters can lead to relatively pure PHA and high PHA recovery.

Additionally, our study shows for the first time that $\mathrm{NH}_{3}$ digestion can lead to a higher thermal stability than achieved using other digestion methods, even with PHA of lower purity. The maximum degradation temperature $\left(T_{d}\right)$ was comparable to solvent-extracted PHA (around $300{ }^{\circ} \mathrm{C}$ ), and much higher than that obtained with $\mathrm{NaOH}$ or $\mathrm{H}_{2} \mathrm{SO}_{4}$ digestions (lower than 270 ${ }^{\circ} \mathrm{C}$ ) (Figure 10). Similarly, a much lower $\mathrm{T}_{\mathrm{d}}$ has been reported for $\mathrm{NH}_{3}$ digestions complemented with lauric acid as surfactant (Table 2). Moreover, $\mathrm{PHA}$ recovered through $\mathrm{NH}_{3}$ digestion presented almost no reduction of the molar mass during melting, while almost complete degradation was observed for $\mathrm{H}_{2} \mathrm{SO}_{4}$ or $\mathrm{NaOH}$ mediated extractions. These observations are of crucial importance for polymer applications. 
Our results showed that a high degree of thermal stability was obtained with PHA purities above $70 \%$ (obtained at temperatures between $75{ }^{\circ} \mathrm{C}$ and $115^{\circ} \mathrm{C}$ ). Higher purities and thermal stability could be achieved at treatments above $75^{\circ} \mathrm{C}$ and including a sonication pre-treatment, but as a trade-off, they led to higher loss of molar mass and would be expected to present higher energy costs. Thus, further optimisation should take into consideration the required purity level and molar mass, which were seen to be very sensitive to operational conditions at elevated temperatures.

The results obtained in this study are very promising also from a sustainability point of view. Besides avoiding the use of a toxic solvent, the digestion solution could be re-used in PHA production process. Previous studies have observed that the use of the digestion solution as a nitrogen source led to even better results than the use of ammonium salts ${ }^{15}$. Moreover, the high $\mathrm{pH}$ of the digestion solution (9-12) could represent a further advantage in processes requiring base addition. In such processes (like the fermentation and enrichment step of three-stage PHA production in $\mathrm{MMC}^{21}$ ), direct addition of this solution could substitute external alkali, and thus lead to additional savings. For each process, a balance between the needs for nitrogen and alkali should be performed, taking into account as well the possibility of reusing the $\mathrm{NH}_{3}$ solution in the following digestion batch. 


\section{Conclusions}

Dilute ammonia digestion of the non-PHA cell material was studied as a method for purifying PHA produced by mixed microbial consortia; a method which could bring important advantages in terms of costs and sustainability due to the possibility of recycling ammonia within the process.

The results showed that the efficiency of the method largely depends on the digestion conditions - especially in regards to the temperature. Low PHA purities (around $64 \%$ ) and PHA recoveries (from 65 to $80 \%$ ) were obtained at mild temperature conditions, with little changes upon increased incubation time or ammonia concentration. On the other hand, treatments performed between $75{ }^{\circ} \mathrm{C}$ and $115^{\circ} \mathrm{C}$ led to high recovery of PHA (above $90 \%$ ) and increased PHA purity, while maintaining the molar mass of PHA at reasonable values. Higher PHA recovery at this temperature range was a result of a lower degree of hydrolysis leading to monomers and soluble oligomers, which was hypothesised to occur as a result of PHA conformational changes at elevated temperatures. A pre-treatment by sonication also proved valuable to further increase the PHA purity without severely impacting the molar mass.

High thermal stability was observed in PHA recovered with $\mathrm{NH}_{3}$ digestion at different conditions when its purity was above $70 \%$. Conversely, almost complete degradation during melting was observed in PHA recovered with other chemicals aiming at digestion of non-PHA cell material (e.g. $\mathrm{H}_{2} \mathrm{SO}_{4}$ ), despite presenting higher purity values (98 \%). Stability during melt after $\mathrm{NH}_{3}$-assisted recovery at $115{ }^{\circ} \mathrm{C}$ with previous sonication was comparable to pure 
chloroform-extracted PHA. This fact further underlined the potential of $\mathrm{NH}_{3}$ digestion as a method for PHA purification.

The study provided the grounds for further optimisation of the method, which would be dependent on the PHA-accumulating culture and the requirements in terms of PHA purity and molar mass. Both parameters were highly sensitive to operational conditions at elevated temperatures.

\section{Acknowledgements}

This work was supported by the European Commission (FP7 Grant Agreement no 613667; acronym: GRAIL) and Technical University of Denmark. Assistance from Liyun Yu for DSC and TGA analyses is highly appreciated.

\section{Supporting information}

Appendix A: Effect of time and $\mathrm{NH}_{3}$ concentration on the molar mass. Appendix B: PHA solidliquid separation. Appendix C: Model of aqueous ammonia species and $\mathrm{pH}$ at varying temperatures. Appendix D: The sharp endotherm peaks in DSC curves. Appendix E: DSC curve of samples purified with reference methods. Appendix F: Comparison of values of PHA purity with different PHA Standards.

\section{References}

1. Koller M, Maršálek L, de Sousa Dias MM and Braunegg G. Producing microbial polyhydroxyalkanoate (PHA) biopolyesters in a sustainable manner. N Biotechnol 37: 24- 
38 (2017). DOI:10.1016/j.nbt.2016.05.001.

2. Bugnicourt E, Cinelli P, Lazzeri A and Alvarez V. Polyhydroxyalkanoate (PHA): Review of synthesis, characteristics, processing and potential applications in packaging. Express Polym Lett 8(11): 791-808 (2014). DOI:10.3144/expresspolymlett.2014.82.

3. Kourmentza C, Plácido J, Venetsaneas N, Burniol-Figols A, Varrone C, Gavala HN and Reis MAM. Recent Advances and Challenges towards Sustainable Polyhydroxyalkanoate (PHA) Production. Bioengineering 4(55): 1-43 (2017).

DOI:10.3390/bioengineering4020055.

4. Koller M, Niebelschütz H and Braunegg G. Strategies for recovery and purification of poly[(R)-3-hydroxyalkanoates] (PHA) biopolyesters from surrounding biomass. Eng Life Sci 13(6): 549-562 (2013). DOI:10.1002/elsc.201300021.

5. Jacquel N, Lo CW, Wei YH, Wu HS and Wang SS. Isolation and purification of bacterial poly(3-hydroxyalkanoates). Biochem Eng J 39(1): 15-27 (2008).

DOI:10.1016/j.bej.2007.11.029.

6. Samori C, Abbondanzi F, Galletti P, Giorgini L, Mazzocchetti L, Torri C and Tagliavini E. Extraction of polyhydroxyalkanoates from mixed microbial cultures: Impact on polymer quality and recovery. Bioresour Technol 189: 195-202 (2015).

DOI:10.1016/j.biortech.2015.03.062. 
7. Patel M, Gapes DJ, Newman RH and Dare PH. Physico-chemical properties of polyhydroxyalkanoate produced by mixed-culture nitrogen-fixing bacteria. Appl Microbiol Biotechnol 82(3): 545-555 (2009). DOI:10.1007/s00253-008-1836-0.

8. Heinrich D, Madkour MH, Al-Ghamdi MA, Shabbaj II and Steinbüchel A. Large scale extraction of poly(3-hydroxybutyrate) from Ralstonia eutropha H16 using sodium hypochlorite. AMB Express 2(1): 59 (2012). DOI:10.1186/2191-0855-2-59.

9 . López-Abelairas M, García-Torreiro M, Lú-Chau T, Lema JM and Steinbüchel A. Comparison of several methods for the separation of poly(3-hydroxybutyrate) from Cupriavidus necator H16 cultures. Biochem Eng J 93: 250-259 (2015). DOI:10.1016/j.bej.2014.10.018.

10. Gobi K and Vadivelu VM. Polyhydroxyalkanoate recovery and effect of in situ extracellular polymeric substances removal from aerobic granules. Bioresour Technol 189: 169-176 (2015). DOI:10.1016/j.biortech.2015.04.023.

11. Villano M, Valentino F, Barbetta A, Martino L, Scandola M and Majone M. Polyhydroxyalkanoates production with mixed microbial cultures: From culture selection to polymer recovery in a high-rate continuous process. $N$ Biotechnol 31(4): 289-296 (2014). DOI:10.1016/j.nbt.2013.08.001.

12. Yu J and Chen LXL. Cost-Effective Recovery and Purification of Polyhydroxyalkanoates by Selective Dissolution of Cell Mass. Biotechnol Prog 22(2): 547-553 (2006). 
DOI:10.1021/bp050362g.

13. Jiang Y, Mikova G, Kleerebezem R, van der Wielen LA and Cuellar MC. Feasibility study of an alkaline-based chemical treatment for the purification of polyhydroxybutyrate produced by a mixed enriched culture. AMB Express 5(1): 5-13 (2015).

DOI:10.1186/s13568-015-0096-5.

14. Yu J, Plackett D and Chen LXL. Kinetics and mechanism of the monomeric products from abiotic hydrolysis of poly[(R)-3-hydroxybutyrate] under acidic and alkaline conditions. Polym Degrad Stab 89(2): 289-299 (2005).

DOI:10.1016/j.polymdegradstab.2004.12.026.

15. Page WJ and Cornish A. Growth of Azotobacter vinelandii UWD in fish peptone medium and simplified extraction of poly- $\beta$-hydroxybutyrate. Appl Environ Microbiol 59(12): 4236-4244 (1993). DOI:10.1007/BF00169430.

16. Godbole S, H F, T C and P K. An improved non solvent based process for extraction and recovery of poly- $\beta$-hydroxybutyrate (PHB). Indian Patent 232481. (2009).

17. Anis SNS, Nurhezreen MI, Sudesh K and Amirul AA. Enhanced recovery and purification of $\mathrm{P}(3 \mathrm{HB}-\mathrm{co}-3 \mathrm{HHx})$ from recombinant Cupriavidus necator using alkaline digestion method. Appl Biochem Biotechnol 167(3): 524-535 (2012). DOI:10.1007/s12010-0129677-9. 
18 . Choi J and Lee SY. Efficient and Economical Recovery of Poly (3-Hydroxybutyrate) from Recombinant Escherichia coli by Simple Digestion with Chemicals. Biotechnol Bioeng 62(5): 546-553 (1999). DOI:10.1002/(SICI)1097-0290(19990305)62:5<546::AIDBIT6>3.0.CO;2-0.

19 . Mannina G, Presti D, Montiel-Jarillo G and Suárez-Ojeda ME. Bioplastic recovery from wastewater: A new protocol for polyhydroxyalkanoates (PHA) extraction from mixed microbial cultures. Bioresour Technol 282: 361-369 (2019).

DOI:10.1016/j.biortech.2019.03.037.

20 . Samorì C, Basaglia M, Casella S, Favaro L, Galletti P, Giorgini L, Marchi D, Mazzocchetti L, Torri C and Tagliavini E. Dimethyl carbonate and switchable anionic surfactants: two effective tools for the extraction of polyhydroxyalkanoates from microbial biomass. Green Chem 17(2): 1047-1056 (2015). DOI:10.1039/C4GC01821D.

21 . Burniol-Figols A, Varrone C, Le SB, Daugaard AE, Skiadas I V. and Gavala HN. Combined polyhydroxyalkanoates (PHA) and 1,3-propanediol production from crude glycerol: Selective conversion of volatile fatty acids into PHA by mixed microbial consortia. Water Res 136: 180-191 (2018). DOI:10.1016/j.watres.2018.02.029.

22. Burniol-Figols A, Varrone C, Egede AD, Le SB, Skiadas I V. and Gavala HN. Polyhydroxyalkanoates (PHA) production from fermented crude glycerol: Study on the conversion of 1,3-propanediol to PHA in mixed microbial consortia. Water Res 128: 255- 
266 (2018). DOI:10.1016/j.watres.2017.10.046.

23. Nunes R, Martin J and Johnson J. Influence of molecular weight and molecular weight distribution on mechanical properties of polymers. Polym Eng Sci 22(4): 205-228 (1982). DOI:10.1002/pen.760220402.

24 . Kanesawa Y and Doi Y. Hydrolytic degradation of microbial poly(3-hydroxybutyrate- co-3-hydroxyvalerate) fibers. Makromol Chemie Rapid Commun 11: 679-682 (1990). DOI:10.1080/15421406.2012.635982.

25. Mohammadi M, Hassan MA, Phang L-Y, Shirai Y, Che Man H, Ariffin H, Amirul AA and Syairah SN. Efficient Polyhydroxyalkanoate Recovery from Recombinant Cupriavidus necator by Using Low Concentration of NaOH. Environ Eng Sci 29(8): 783789 (2012). DOI:10.1089/ees.2011.0255.

26. Xiang H, Wen X, Miu X, Li Y, Zhou Z and Zhu M. Thermal depolymerization mechanisms of poly(3-hydroxybutyrate-co-3-hydroxyvalerate). Prog Nat Sci Mater Int 26(1): 58-64 (2016). DOI:10.1016/j.pnsc.2016.01.007.

27. Olofsson G. Thermodynamic quantities for the dissociation of the ammonium ion and for the ionization of aqueous ammonia over a wide temperature range. J Chem Thermodyn 7(6): 507-514 (1975). DOI:10.1016/0021-9614(75)90183-4.

28. Hilliou L, Diogo M, Oliveria CSS, Gouveia AR, Reis MAM, Campari S, Villano M and 
Majorne M. Impact of fermentation residues on the thermal, structural, and rheological properties of polyhydroxy(butyrate-co-valerate) produced from cheese whey and olive oil mill wastewater. J Appl Polym Sci 133(2) (2016). doi:10.1002/APP.42818

DOI:10.1002/APP.42818.

29. Biddlestone F, Harris A, Hay JN and Hammond T. The physical ageing of amorphous poly(hydroxybutyrate). Polym Int 39(3): 221-229 (1996). DOI:10.1002/(SICI)10970126(199603)39:3<221::AID-PI511>3.0.CO;2-O.

30. Di Lorenzo ML, Gazzano M and Righetti MC. The role of the rigid amorphous fraction on cold crystallization of poly(3-hydroxybutyrate). Macromolecules 45(14): 5684-5691 (2012). DOI:10.1021/ma3010907.

31. Kurusu RS, Demarquette NR, Gauthier C and Chenal JM. Effect of ageing and annealing on the mechanical behaviour and biodegradability of a poly(3-hydroxybutyrate) and poly(ethylene-co-methyl-acrylate-co-glycidyl-methacrylate)blend. Polym Int 63(6): 10851093 (2014). DOI:10.1002/pi.4616.

32 . de Koning GJM and Lemstra PJ. The amorphous state of bacterial poly[(R)-3hydroxyalkanoate]in vivo. Polymer (Guildf) 33(15): 3292-3294 (1992). DOI:10.1016/0032-3861(92)90249-V.

33. Crétois R, Chenal JM, Sheibat-Othman N, Monnier A, Martin C, Astruz O, Kurusu R and Demarquette NR. Physical explanations about the improvement of PolyHydroxyButyrate 
ductility: Hidden effect of plasticizer on physical ageing. Polymer (Guildf) 102: 176-182 (2016). DOI:10.1016/j.polymer.2016.09.017.

34 . Peng J, Wen K, Liu W, Yue X, Wang A and Zhou A. EPS solubilization and waste activated sludge acidification enhanced by alkaline-assisted bi-frequency ultrasonic pretreatment revealed by 3D-EEM fluorescence. RSC Adv 6(84): 80493-80500 (2016). DOI:10.1039/C6RA19521K.

35. D’Abzac P, Bordas F, Van Hullebusch E, Lens PNL and Guibaud G. Extraction of extracellular polymeric substances (EPS) from anaerobic granular sludges: Comparison of chemical and physical extraction protocols. Appl Microbiol Biotechnol 85(5): 1589-1599 (2010). DOI:10.1007/s00253-009-2288-X.

36. Grassie N, Murray EJ and Holmes PA. The Thermal Tegradation of Poly(-(D)- $\beta$ Hydroxybutyric acid): Part 2-Changes in Molecular Weight. Polym Degrad Stab 6(2): 95103 (1984). DOI:10.1016/0141-3910(84)90075-2.

37 . Hablot E, Bordes P, Pollet E and Avérous L. Thermal and thermo-mechanical degradation of poly(3-hydroxybutyrate)-based multiphase systems. Polym Degrad Stab 93(2): 413421 (2008). DOI:10.1016/j.polymdegradstab.2007.11.018.

38 . Martínez-Abad A, Cabedo L, S.S.Oliveira C, Hilliou L, Reis M and Lagarón JM. Characterization of polyhydroxyalkanoate blends incorporating unpurified biosustainably produced poly(3-hydroxybutyrate-co-3- hydroxyvalerate). J Appl Polym Sci 133(2) 
(2016). doi:10.1002/app.42971 DOI:10.1002/app.42971. 
Table 1: PHA purity, type of impurities and melting temperature $\left(T_{m}\right)$ of samples purified through ammonia digestion or other comparison methods.

\begin{tabular}{|c|c|c|c|c|c|c|c|}
\hline Sample & Purification method & $\begin{array}{c}\text { PHA } \\
\text { recovery (\%) }\end{array}$ & $\begin{array}{l}\text { PHA purity } \\
(\%) \mathrm{GC}^{*}\end{array}$ & $\begin{array}{l}\text { PHA purity } \\
(\%) \text { TGA }^{* *}\end{array}$ & $\begin{array}{c}\text { Organic } \\
\text { impurities } \\
(\%)^{\dagger}\end{array}$ & $\begin{array}{c}\text { Inorganic } \\
\text { impurities } \\
(\%)^{\dagger}\end{array}$ & $\begin{array}{c}\mathrm{T}_{\mathrm{m}} \\
\left({ }^{\circ} \mathrm{C}\right)^{\dagger+}\end{array}$ \\
\hline Crude PHA & -- & -- & $64 \pm 1.2$ & 69 & 16.8 & 9.9 & 156 \\
\hline Chloroform & $\begin{array}{l}\text { Chloroform } 65^{\circ} \mathrm{C} 4 \mathrm{~h}+ \\
\text { methanol precipitation }\end{array}$ & n.d. & $99 \pm 0.2$ & 99 & 0.03 & 0.8 & 162 \\
\hline $\mathrm{NaOH}$ & $\mathrm{NaOH} 0.2 \mathrm{M} 30^{\circ} \mathrm{C} 60 \mathrm{~min}$ & $90 \pm 0.9$ & $72 \pm 0.8$ & 76 & 13.4 & 6.8 & 152 \\
\hline $\mathrm{NaOH}$ SDS & $\begin{array}{c}(\mathrm{NaOH} 0.2 \mathrm{M}+\mathrm{SDS} 0.2 \%) \\
30^{\circ} \mathrm{C} 60 \mathrm{~min}\end{array}$ & $91 \pm 0.9$ & $76 \pm 0.9$ & 76 & 13.4 & 6.2 & 154 \\
\hline $\mathrm{H}_{2} \mathrm{SO}_{4}$ & $\begin{array}{c}\mathrm{H}_{2} \mathrm{SO}_{4} 3.5 \% 80{ }^{\circ} \mathrm{C} 6 \mathrm{~h}+ \\
\text { NaOCl } 3 \% 1 \text { room T }\end{array}$ & $97 \pm 2.5$ & $98 \pm 2.6$ & 97 & 1.3 & 0.8 & 147 \\
\hline $\mathrm{NH}_{3}$ & $\begin{array}{c}\text { sonication }+\mathrm{NH}_{3} 0.2 \mathrm{M} \\
115^{\circ} \mathrm{C} 30 \mathrm{~min}\end{array}$ & $92 \pm 0.2$ & $86 \pm 0.8$ & 89 & 5.1 & 2.8 & 154 \\
\hline
\end{tabular}

* PHA purity (g PHA/100 g Total solids) measured by Gas Chromatography

** PHA purity (g PHA/100 g Total solids) measured from the slope of the TGA curve

†Determined from the TGA curve

††Determined from the DSC curves in Figure S 7 (Appendix E)

n.d. not determined 
Table 2: Comparison of results obtained with ammonia digestion published in the scientific literature.

\begin{tabular}{|c|c|c|c|c|c|c|c|c|c|c|c|c|c|c|}
\hline Ref & Polymer & Culture & $\begin{array}{l}\text { Biomass } \\
\text { state }\end{array}$ & $\begin{array}{c}\text { Pre- } \\
\text { treatment }\end{array}$ & Conc. $\mathrm{NH}_{3}$ & $\mathrm{~T}\left({ }^{\circ} \mathrm{C}\right)$ & $\mathrm{t}(\min )$ & $\begin{array}{l}\text { Post- } \\
\text { treatment }\end{array}$ & $\begin{array}{l}\text { PHA ini } \\
\text { (wt \%) }\end{array}$ & $\begin{array}{c}\text { PHA } \\
\text { Purity (wt } \\
\%)^{* *}\end{array}$ & $\begin{array}{c}\text { PHA } \\
\text { Recovery } \\
(\%)\end{array}$ & $\begin{array}{c}\overline{\mathrm{M}_{\mathrm{w}}} \text { ref } \\
(\mathrm{kg} / \mathrm{mol})^{*}\end{array}$ & $\begin{array}{l}\overline{\mathrm{M}_{\mathrm{w}}} \text { final } \\
(\mathrm{kg} / \mathrm{mol})^{* * *}\end{array}$ & $\begin{array}{c}\mathrm{T}_{\mathrm{d}} \\
(\square \mathrm{C})\end{array}$ \\
\hline \multirow[t]{2}{*}{15} & \multirow{2}{*}{ РЗНВ } & \multirow{2}{*}{$\begin{array}{l}\text { Azobacter } \\
\text { vienlandii }\end{array}$} & \multirow{2}{*}{$\begin{array}{c}\text { wet } \\
\text { biomass }\end{array}$} & \multirow{2}{*}{--} & \multirow{2}{*}{$1 \mathrm{~N}$} & 45 & \multirow{2}{*}{10} & & 84 & 94 & \multirow{2}{*}{ n.r. } & \multirow{2}{*}{$1700-2700$} & \multirow{2}{*}{$1700-2700$} & n.r. \\
\hline & & & & & & 100 & & & 83 & 92 & & & & n.r. \\
\hline \multirow{3}{*}{13} & \multirow{3}{*}{ РЗНB } & \multirow{3}{*}{ MMC } & $\begin{array}{c}\text { wet } \\
\text { biomass }\end{array}$ & -- & \multirow{3}{*}{$0.2 \mathrm{M}$} & \multirow{3}{*}{30} & \multirow{3}{*}{60} & & 68.6 & 62.6 & 63.3 & \multirow{3}{*}{ n.r. } & \multirow{3}{*}{ n.r. } & n.r. \\
\hline & & & & & & & & & & & & & & \\
\hline & & & $\begin{array}{l}\text { freeze } \\
\text { dried }\end{array}$ & -- & & & & & 69.9 & 87.4 & 95 & & & n.r. \\
\hline 16 & P3HB & $\begin{array}{c}\text { Alcaligenes } \\
\text { latus }\end{array}$ & $\begin{array}{c}\text { wet } \\
\text { biomass }\end{array}$ & - & $5-10 \mathrm{~N}$ & $60-100$ & $60-120$ & $\begin{array}{c}\mathrm{NaOCl} 4-6 \\
\%\end{array}$ & n.r. & 92 & n.r. & n.r. & n.r. & n.r. \\
\hline 18 & Р3HB & $\begin{array}{l}\text { Escherichia } \\
\text { coli }\end{array}$ & $\begin{array}{c}\text { wet } \\
\text { biomass }\end{array}$ & -- & $0.1 \mathrm{~N}$ & 30 & 60 & & 77 & 85.4 & 94.7 & n.r. & n.r. & n.r. \\
\hline 17 & $\begin{array}{c}\mathrm{P}(3 \mathrm{HB}-c o- \\
\text { ЗНHx) }\end{array}$ & $\begin{array}{l}\text { Cupriavidus } \\
\text { necator }\end{array}$ & $\begin{array}{l}\text { freeze } \\
\text { dried }\end{array}$ & -- & $0.1 \mathrm{M}$ & 30 & 60 & & 60 & $\approx 60$ & $\approx 62$ & n.r. & n.r. & n.r. \\
\hline \multirow{2}{*}{20} & \multirow[b]{2}{*}{ РЗНВ } & \multirow{2}{*}{$\begin{array}{l}\text { Cupravirus } \\
\text { necator }\end{array}$} & \multirow{2}{*}{$\begin{array}{l}\text { freeze } \\
\text { dried }\end{array}$} & -- & $0.1 \mathrm{M}$ & 90 & 180 & & & $\approx 70$ & $\approx 78$ & & 700 & 272 \\
\hline & & & & -- & $\begin{array}{c}0.25 \mathrm{M} \mathrm{NH}_{3-}^{-} \\
\text {laurate }\end{array}$ & 90 & 180 & & 74 & 98 & 100 & 1200 & 600 & 264 \\
\hline \multirow{2}{*}{19} & P3HB & \multirow[b]{2}{*}{ MMC } & \multirow{2}{*}{$\begin{array}{l}\text { freeze } \\
\text { dried }\end{array}$} & -- & $0.1 \mathrm{~N}$ & 90 & 180 & & 52 & $50^{\dagger}$ & $75^{\dagger}$ & n.r. & n.r. & n.r. \\
\hline & $\begin{array}{l}\text { P(3HB-co- } \\
\text { 3HV) }\end{array}$ & & & $\begin{array}{c}\mathrm{NaOCl} 4.7 \\
\%\end{array}$ & $\begin{array}{c}0.2 \mathrm{M} \mathrm{NH}_{3}- \\
0.13 \mathrm{M} \text { laurate }\end{array}$ & 75 & 180 & & $52-54$ & 93 & 73 & n.r. & 144 & 220 \\
\hline
\end{tabular}

This article is protected by copyright. All rights reserved. 


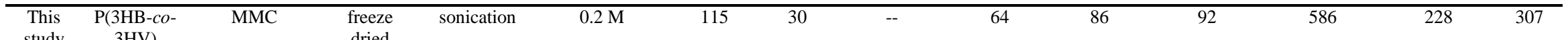

n r.: decomposition
d... 

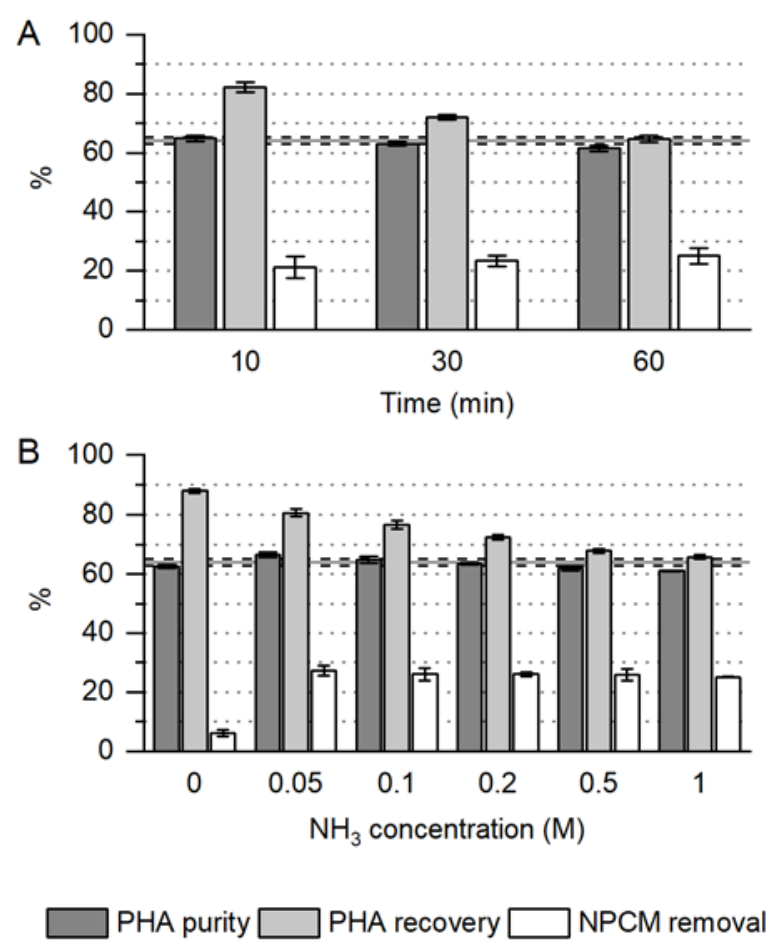

Figure 1: Effect of Time (A) and $\mathrm{NH}_{3}$ concentration (B) on the PHA purity, PHA recovery and Non-PHA Cell Material (NPCM) removal during ammonia digestion. A: Time effect $\left(\mathrm{T}: 45^{\circ} \mathrm{C}\right.$, $\left.\mathrm{NH}_{3}: 0.2 \mathrm{M}\right) . \mathrm{B}: \mathrm{NH}_{3}$ concentration effect $\left(\mathrm{T}: 45^{\circ} \mathrm{C}\right.$, t: $\left.30 \mathrm{~min}\right)$. The line across bars indicates the PHA purity of the material before digestion (crude PHA). 

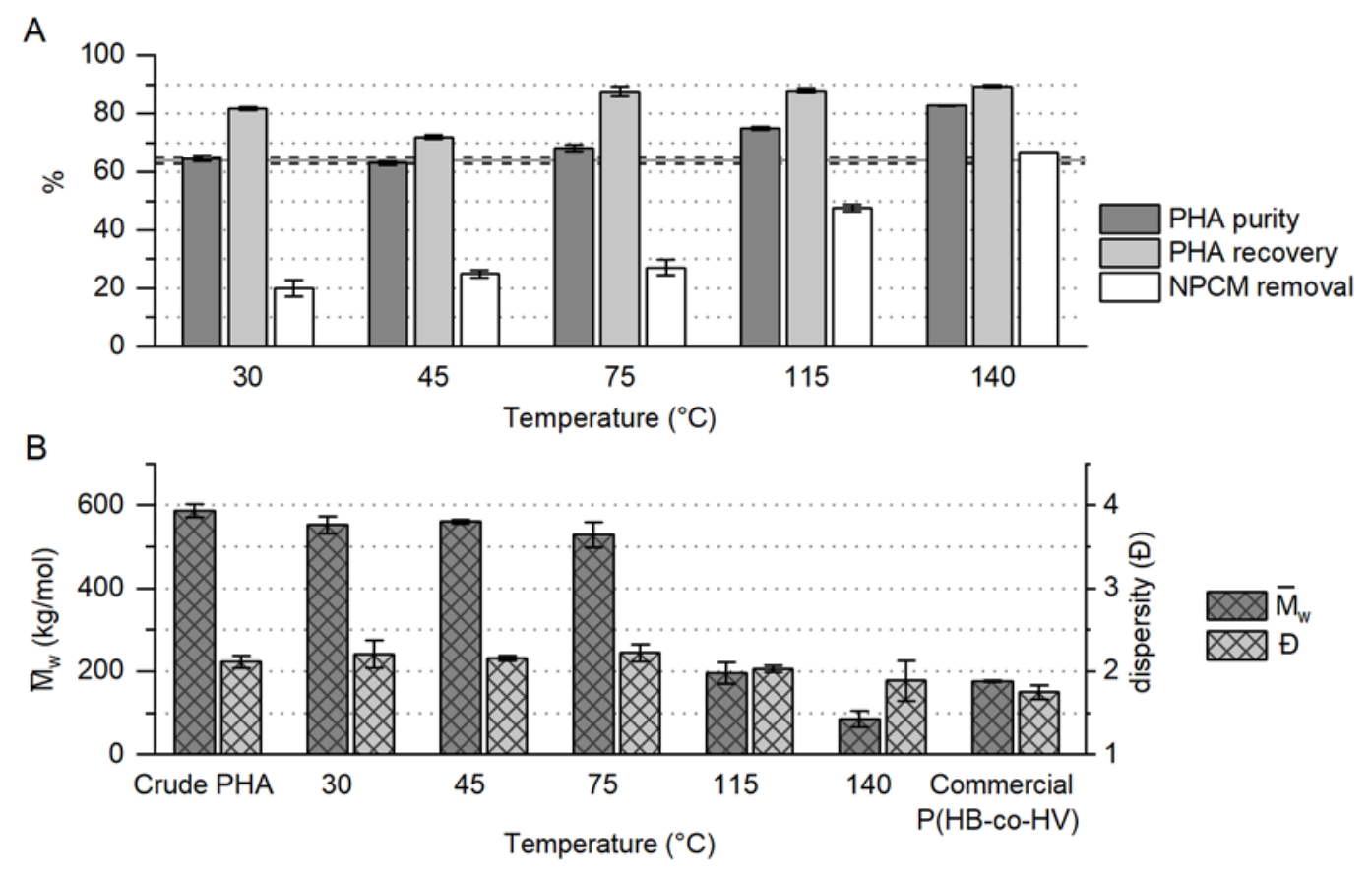

Figure 2: A: Effect of temperature during ammonia digestion on the PHA purity, PHA recovery and Non-PHA Cell Material (NPCM) removal (t: $30 \mathrm{~min}, \mathrm{NH}_{3}: 0.2 \mathrm{M}$ ). The line across bars indicates the PHA purity of the material before digestion (crude PHA). B: Weight-average molar mass $\left(\overline{\mathrm{M}_{\mathrm{w}}}\right)$ and dispersity $(\mathrm{P})$ in the range of 30 to $140{ }^{\circ} \mathrm{C}$. 

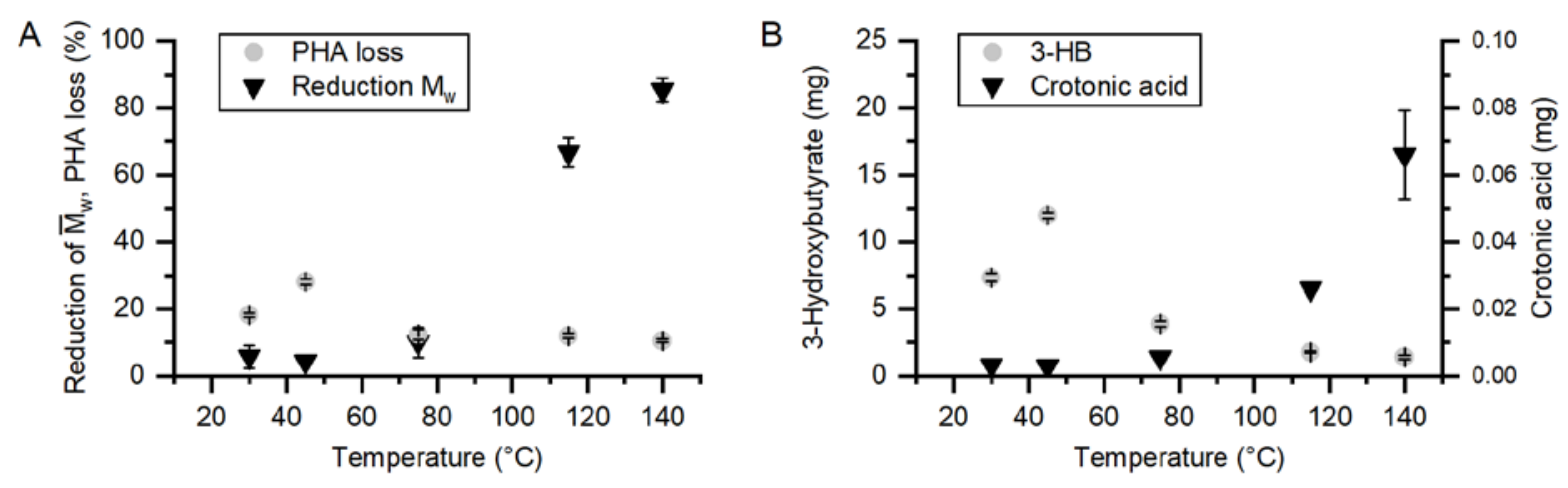

Figure 3: A: Reduction of weight-average molar mass $\left(\overline{\mathrm{M}_{\mathrm{w}}}\right)(\%)$ and PHA loss (\%) in the experiments performed with $\mathrm{NH}_{3} 0.2 \mathrm{M}$ during $30 \mathrm{~min}$ at different temperatures. B: 3hydroxybutyrate (3-HB) and crotonic acid detected in the supernatant of the experiments in A. 
A

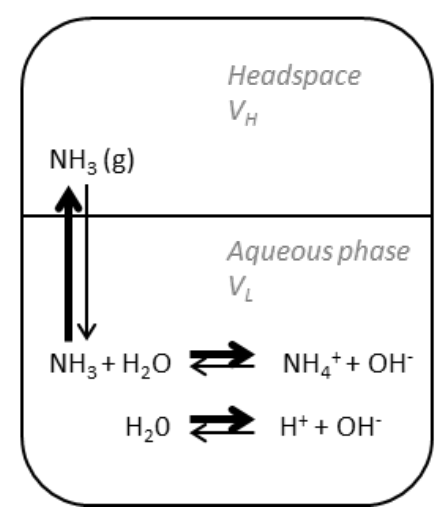

B

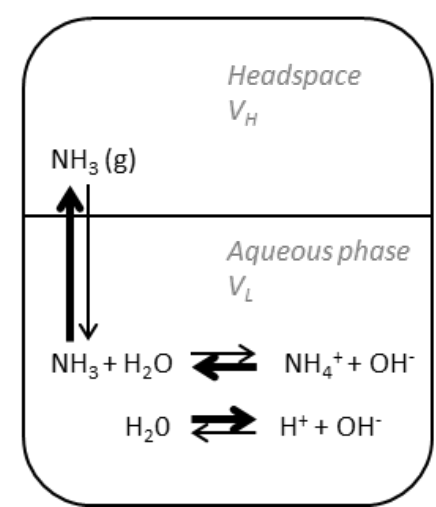

Figure 4: Shift of the equilibrium reactions with the increase of temperature from 0 to $50{ }^{\circ} \mathrm{C}$ (A) and from 50 to $140{ }^{\circ} \mathrm{C}$ (B). The direction of the shift is indicated by the bold arrows. 


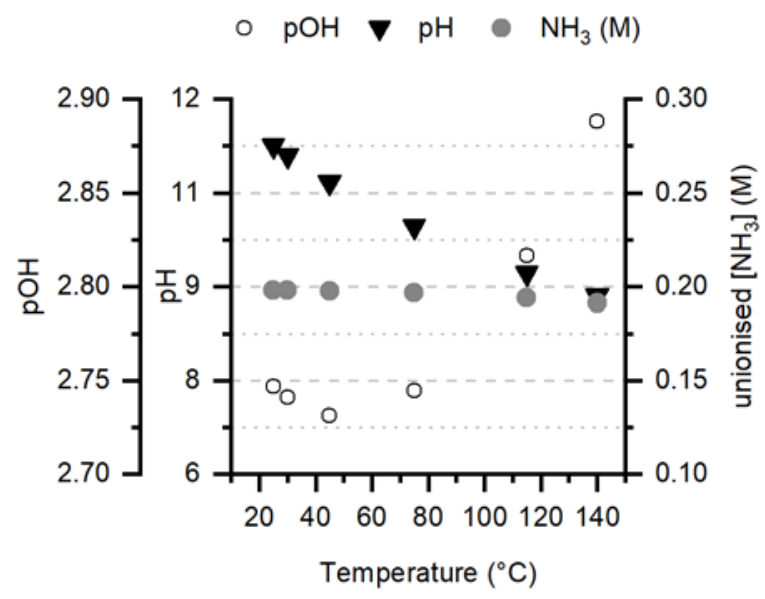

Figure 5: $\mathrm{pH}, \mathrm{pOH}$ and concentration of unionised $\mathrm{NH}_{3}$ obtained with the model at varying temperatures $\left(25-140^{\circ} \mathrm{C}\right)$ and constant initial concentration of ammonia (0.2 M). 

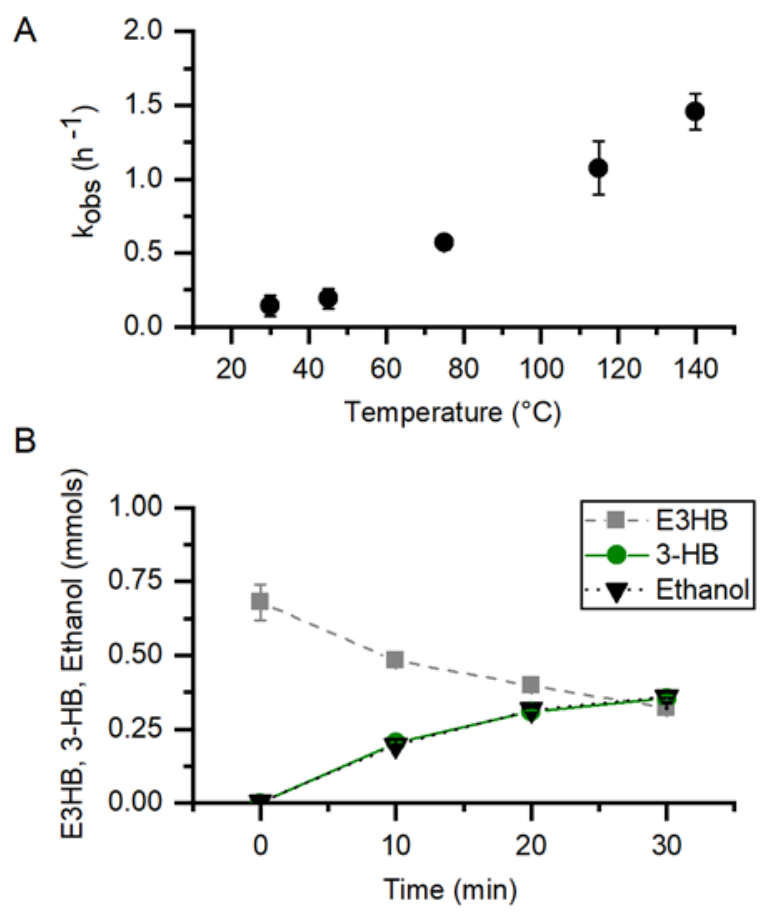

Figure 6: A: Hydrolysis constant observed with incubations of ethyl-3-hydroxybutyrate with $0.2 \mathrm{M} \mathrm{NH}_{3}$ at different temperatures. B: Ethyl-3-hydroxybutyrate (E3HB), 3-hydroxybutyrate (3$\mathrm{HB}$ ) and ethanol detected during the hydrolysis of E3HB with $\mathrm{NH}_{3} 0.2 \mathrm{M}$ at $140{ }^{\circ} \mathrm{C}$. 


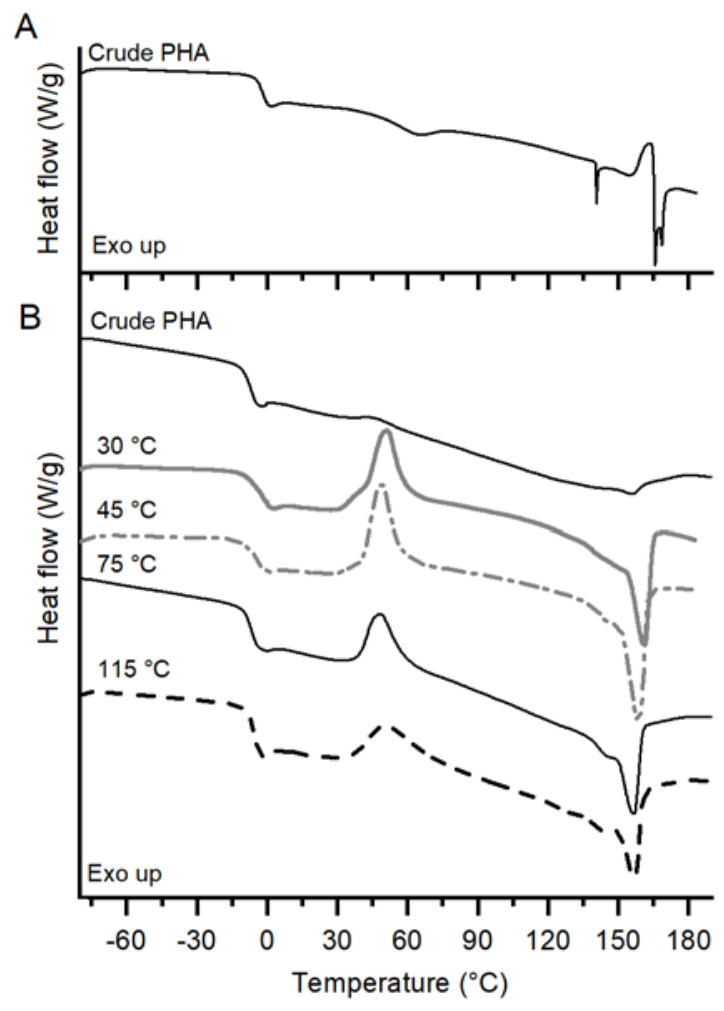

Figure 7: DSC curves recorded for crude $\mathrm{PHA}$ and $\mathrm{NH}_{3}$-digested samples $\left(0.2 \mathrm{M} \mathrm{NH}_{3}\right.$ for 30 min at different temperatures). A: Run I (first heating ramp) of crude PHA. B: Run II (second heating ramp) of crude $\mathrm{PHA}$ and $\mathrm{NH}_{3}$-digested samples. 


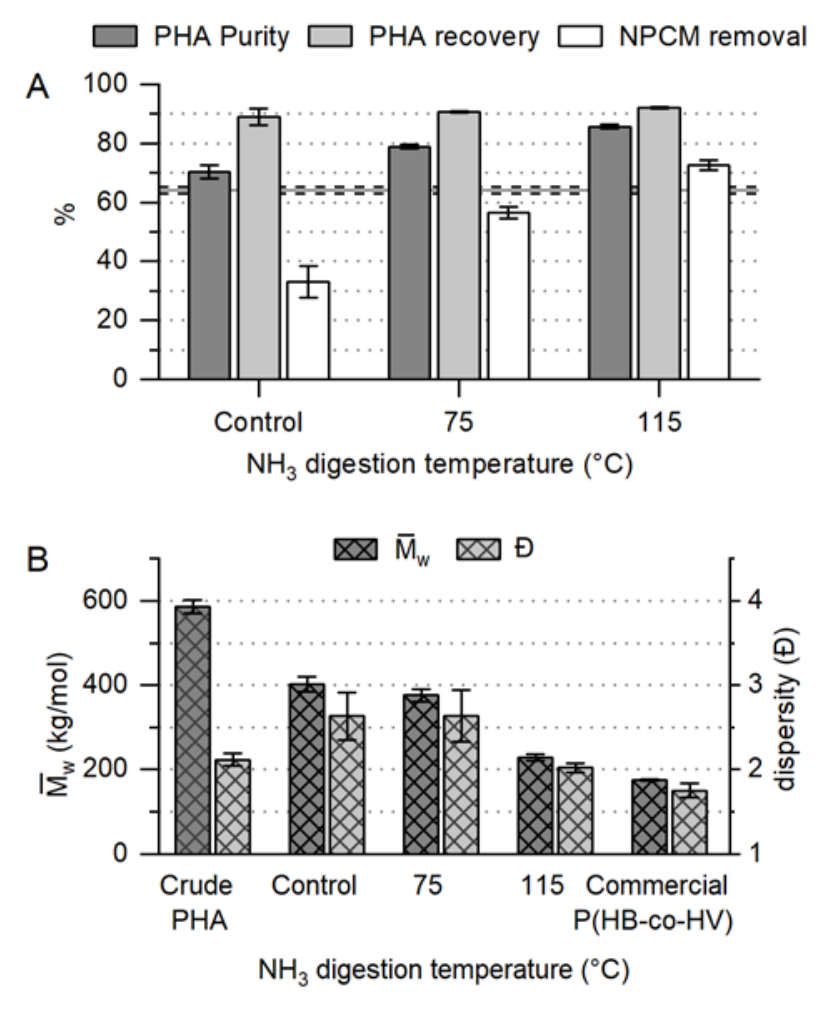

Figure 8: Combined sonication and ammonia digestion at high temperatures, performed with incubations of 30 min with $0.2 \mathrm{M} \mathrm{NH}_{3}$. Only sonication but no ammonia digestion was performed on the control samples. A: PHA purity, PHA recovery and Non-PHA cell material (NPCM) removal. The line across bars indicates the PHA purity of the material before digestion (crude PHA). B: Weight-average molar mass $\left(\overline{\mathrm{M}_{\mathrm{w}}}\right)$ and dispersity (Đ). 


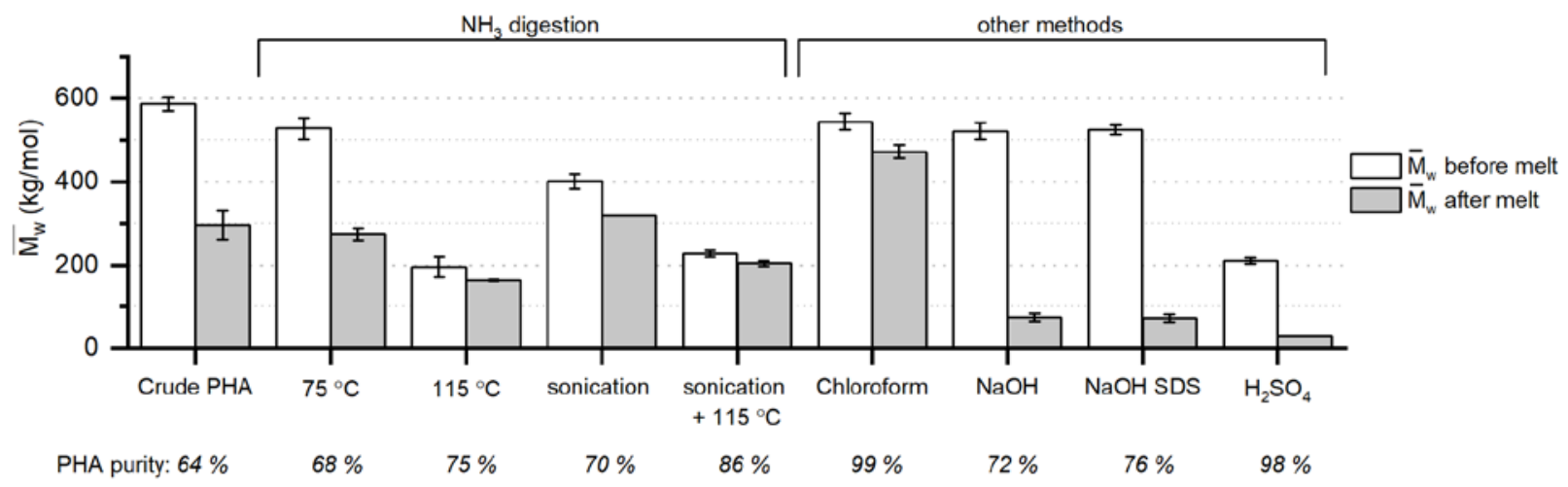

Figure 9: Molar mass $\left(\overline{\mathrm{M}_{\mathrm{w}}}\right)$ change during melting of the purified PHA (5 min $\left.170{ }^{\circ} \mathrm{C}\right)$. White bars indicate the $\overline{\mathrm{M}_{\mathrm{w}}}$ after purification (before melting), and grey bars represent the $\overline{\mathrm{M}_{\mathrm{w}}}$ after melting. Samples purified through $\mathrm{NH}_{3}$ digestion: $75^{\circ} \mathrm{C} 0.2 \mathrm{M} \mathrm{NH}_{3} ; 115^{\circ} \mathrm{C} 0.2 \mathrm{M} \mathrm{NH}_{3}$; sonication without $\mathrm{NH}_{3}$ digestion; and sonication followed by $115{ }^{\circ} \mathrm{C} 0.2 \mathrm{M} \mathrm{NH}_{3}$. Other methods: See Table 1. PHA purity of the samples after purification is indicated below the $\mathrm{x}$ axis. 

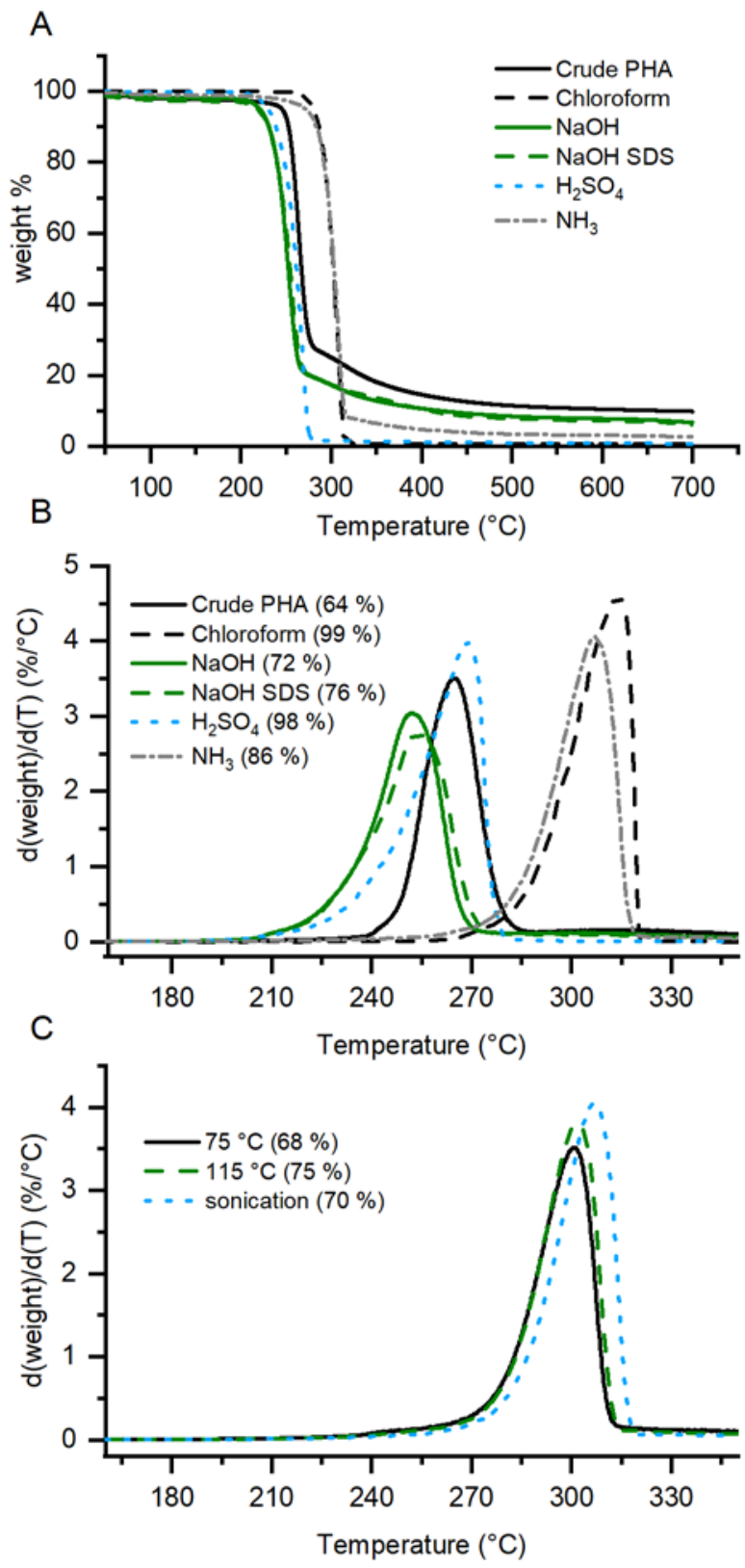

Figure 10: TGA curves. A: Weight \% vs. temperature in samples purified through $\mathrm{NH}_{3}$ digestion at $115{ }^{\circ} \mathrm{C}(0.2 \mathrm{M})$ with previous sonication compared to other reference methods and the crude PHA. B: Derivate of the weight \% vs. 
temperature of the samples in A in the temperature range of PHA degradation. C: Derivate of the weight \% vs. temperature of samples obtained through different $\mathrm{NH}_{3}$ digestion conditions: $75{ }^{\circ} \mathrm{C} 0.2 \mathrm{M} \mathrm{NH}_{3}, 115{ }^{\circ} \mathrm{C} 0.2 \mathrm{M}$ NH3 and sonication without $\mathrm{NH}_{3}$ digestion. Values in parenthesis in the legends indicate PHA purity. 